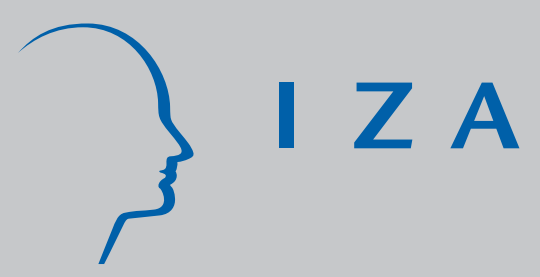

IZA DP No. 3067

How General Is Human Capital? A Task-Based Approach

Christina Gathmann

Uta Schönberg

September 2007 


\title{
How General Is Human Capital? A Task-Based Approach
}

\author{
Christina Gathmann \\ Stanford University \\ and IZA \\ Uta Schönberg \\ University of Rochester \\ and IZA
}

\section{Discussion Paper No. 3067 \\ September 2007}

\author{
IZA \\ P.O. Box 7240 \\ 53072 Bonn \\ Germany \\ Phone: +49-228-3894-0 \\ Fax: +49-228-3894-180 \\ E-mail: iza@iza.org
}

\begin{abstract}
Any opinions expressed here are those of the author(s) and not those of the institute. Research disseminated by IZA may include views on policy, but the institute itself takes no institutional policy positions.

The Institute for the Study of Labor (IZA) in Bonn is a local and virtual international research center and a place of communication between science, politics and business. IZA is an independent nonprofit company supported by Deutsche Post World Net. The center is associated with the University of Bonn and offers a stimulating research environment through its research networks, research support, and visitors and doctoral programs. IZA engages in (i) original and internationally competitive research in all fields of labor economics, (ii) development of policy concepts, and (iii) dissemination of research results and concepts to the interested public.
\end{abstract}

IZA Discussion Papers often represent preliminary work and are circulated to encourage discussion. Citation of such a paper should account for its provisional character. A revised version may be available directly from the author. 


\begin{abstract}

\section{How General Is Human Capital? A Task-Based Approach ${ }^{*}$}

This paper studies how portable skill accumulated in the labor market are. Using rich data on tasks performed in occupations, we propose the concept of task-specific human capital to measure the transferability of skills empirically. Our results on occupational mobility and wages show that labor market skills are more portable than previously considered. We find that individuals move to occupations with similar task requirements and that the distance of moves declines with time in the labor market. We also show that task-specific human capital is an important source of individual wage growth, in particular for university graduates. For them, at least 40 percent of overall wage growth over a ten year period can be attributed to task-specific human capital. For the low- and medium-skilled, task-specific human capital accounts for at least 35 and 25 percent of overall wage growth respectively.
\end{abstract}

JEL Classification: J24, J31

Keywords: $\quad$ human capital, skill transferability, wage growth, occupations, Germany

Corresponding author:

Christina Gathmann

Hoover Institution

Stanford University

Stanford, CA 94305-6010

USA

E-mail: cgathman@stanford.edu

\footnotetext{
*We thank Katherine Abraham, Min Ahn, Mark Bils, Nick Bloom, Susan Dynarski, Anders Frederiksen, Donna Ginther, Galina Hale, Bob Hall, Henning Hillmann, Pete Klenow, Ed Lazear, Petra Moser, John Pencavel, Luigi Pistaferri, Richard Rogerson, Michele Tertilt, participants at the Society of Labor Economists Meeting, the Society of Economic Dynamics Meeting, the World Congress of the Econometric Society and numerous institutions for helpful comments and suggestions. All remaining errors are our own.
} 


\section{Introduction}

Human capital theory (Becker, 1964; Mincer, 1974) and job search models (e.g. Jovanovic, 1979a; 1979b) are central building blocks for economic models of the labor market. Both are widely used to study job mobility behavior, wage determination and their aggregate implications for wage inequality, unemployment and economic growth.

A crucial decision in these models is how to characterize labor market skills. Human capital and job search theories typically distinguish between general skills like education and experience and specific skills that are tied to a firm or occupation. Important recent contributions have especially focused on the role of specific skills, i.e. the idea that skills are not portable across jobs, to explain phenomena like the growth differences between continental Europe and the United States (e.g. Wasmer, 2004), the rise of unemployment in continental Europe (e.g. Ljungqvist and Sargent, 2005) and the surge in wage inequality over the past decades (e.g. Violante, 2002; Kambourov and Manovskii, 2004).

In this paper, we ask how general or specific skills accumulated on the job actually are in the data. In particular, we demonstrate that labor market skills are more transferable than previously considered. We propose a new way to characterize the specificity of skills using the concept of 'task-specific human capital'. The basic idea of our approach is straightforward. Suppose there are two types of tasks performed in the labor market, for example analytical and manual tasks. Both tasks are general in the sense that they are productive in many occupations. Occupations combine these two tasks in different ways. For example, one occupation (e.g. accounting) relies heavily on analytical tasks, a second one (e.g. bakers) more on manual tasks, and a third combines the two in equal proportion (e.g. musicians).

Skills accumulated in an occupation are then 'specific' because they are only productive in occupations which place a similar value on combinations of tasks (see also Lazear, 2003). This type of task-specific human capital differs from general skills because it is valuable only in occupations that require skills similar to the current one. It differs from occupation-specific skills in that it does not fully depreciate if an individual leaves his occupation. Compare, for instance, a carpenter who decides to become a cabinet maker with a carpenter who decides to become a baker. In our approach, the 
former can transfer more skills to his new occupation than the latter. The partial transferability of skills across occupations has important consequences for occupational mobility and wages. It implies that individuals are more likely to move to occupations with skills requirements similar to their current occupation. It also implies that task-specific human capital, our measure of the transferability of skills across occupations, will be an important source of individual wage growth compared to general or more specific labor market skills.

Our particular data set is uniquely suited to analyze the transferability of skills empirically. It combines information on tasks performed in different occupations with a high-quality panel on complete job histories and wages. The first data is a large panel that follows individual labor market careers from 1975 to 2001. The data, derived from a two percent sample of all social security records in Germany, provides a complete picture of job mobility and wages for more than a 100,000 workers. It has several distinct advantages over the data used in the previous literature on occupational mobility. First, the administrative nature of our data ensures that there is little measurement error in wages and occupational coding. Both are serious problems in data sets like the PSID or NLSY used previously. Furthermore, we have much larger samples available than in typical household surveys.

The third advantage of our data is that we can measure what tasks are performed in different occupations. This information comes from a large survey of 30,000 employees at four separate points in time. Exploiting the variation in task usage across occupations and time, we construct a continuous measure of skill distance between occupations. Based on the task data, the skill requirements of a baker and a cook are very similar. In contrast, switching from a banker to an unskilled construction worker would be the most distant move observable in our data. We then use this skill distance measure together with the panel on job mobility to construct an individual's task-human capital.

Our findings on mobility and wages suggest that human capital is empirically more transferable than previously considered. We find that individuals are much more likely to move to similar occupations than suggested by undirected search and turnover models. The distance of actual moves like the propensity to switch occupations declines sharply with labor market experience. These results are consistent with 
the idea that task-specific human capital is an important determinant of occupational mobility. If human capital is task-specific and therefore transferable to similar occupations, this should also be reflected in individuals' wages. Our framework explains why tenure in the pre-displacement job has been found to have a positive effect on the post-displacement wage (Kletzer, 1989). We also show that wages and tenure in the last occupation have a stronger effect on wages in the new occupation if the two occupations require similar skills.

We then quantify the contribution of task-specific human capital to individual wage growth relative to other general and specific skills, using a control function approach. Our estimates show that taskspecific human capital is an important determinant of individual wage growth. For university graduates, at least 40 percent of wage growth due to human capital accumulation can be attributed to task-specific skills, while occupation-specific skills and experience account for 14 and 47 percent respectively. For the medium-skilled (low-skilled), at least 25 (35) percent of individual wage growth is due to task-specific human capital.

We use our estimates to calculate hypothetical wage loss due job displacement. We find that wage losses due to displacement are partially avoided because workers are able to find employment in occupations that require similar skills. For instance, for the high-skilled, wage losses would be more than twice as large if they were randomly allocated to occupations after displacement.

The paper makes several contributions to the literature. First, we introduce a novel way to define how occupations are related to each other in terms of their skill requirements. In particular, we use data on actual tasks performed in occupations to characterize the distance between occupations along a continuous scale. Previous empirical papers on the transferability of skills across occupations (Shaw, 1984; 1987) have used the frequency of occupational switches to define similar occupations (i.e. occupations that often exchange workers are assumed to have similar skill requirements). ${ }^{1} \mathrm{~A}$ further important difference is that we can analyze empirically both the distance of occupational moves and the contribution of task-specific human capital to wage growth over the life cycle.

\footnotetext{
${ }^{1}$ See also Poletaev and Robinson (2004) who use a discrete measure to define similar occupations.
} 
Second, using our distance measure, we document novel patterns in mobility that are consistent with our view that specific labor market skills are more portable than previously considered. A key implication of our framework, which we confirm with our data, is that the source occupation has a strong influence on the choice of one's future occupation. The literature on firm and occupational mobility in contrast focuses on the determinants of switching firms (Flinn, 1986; Topel and Ward, 1992) or both firms and occupations (McCall, 1990; Miller, 1984; Neal, 1998; Pavan, 2005), but has not studied the type and direction of a move. ${ }^{2}$

Our third contribution is to quantify the contribution of task-specific human capital to individual wage growth and compare it to other forms of human capital like experience and occupational tenure. While a large number of studies have estimated the contribution of firm-specific human capital to individual wage growth (Abraham and Farber, 1987; Altonji and Shakotko, 1987; Altonji and Williams, 2005; Topel, 1991; Kletzer, 1989) ${ }^{3}$, recent evidence suggests that specific skills might be more tied to an occupation than to a particular firm (Gibbons et al., 2006; Kambourov and Manovskii, 2007; Parent, 2000; Neal, 1999). We show in contrast that specific human capital is not fully lost if an individual leaves an occupation. On the contrary, task-specific skills are an important determinant of wage growth over the life-cycle.

Finally, our paper provides the first attempt to integrate the recent literature using task data (Autor et al., 2003; Spitz-Öner, 2006; Borghans et al., 2006) with human capital models of the labor market. ${ }^{4}$ Our paper employs data on tasks to propose a new measure of the specificity of skills. In contrast to the literature on task usage, we abstract from which particular task (analytical, manual etc.) matters for mobility and wages. Instead, we explore the implications of task-specific human capital for occupational mobility, the direction of the occupational move, and the transferability of human capital.

\footnotetext{
${ }^{2}$ In a paper complementary to ours, Malamud (2005) analyzes how the type of university education affects occupational choice and mobility.

${ }^{3}$ See Farber (1999) for a comprehensive survey of this literature.

${ }^{4}$ Autor et al. (2003) for the United States and Spitz-Öner (2006) for West Germany study how technological change has affected the usage of tasks, while Borghans et al. (2006) show how the increased importance of interactive skills has improved the labor market outcomes of under-represented groups. Similarly, Ingram and Neumann (2006) argue that changes in the returns to tasks performed on the job are an important determinant of wage differentials across education groups.
} 
The paper proceeds as follows. The next section outlines our concept of task human capital and how it relates to the previous literature on labor market skills. Section 3 introduces the two data sources and explains how we measure the distance between occupations in terms of their task requirements. The empirical results on the similarity of occupational moves and its implications for wages across occupations are presented in Section 4. Section 5 quantifies the importance of task-specific human capital for individual wage growth. Section 6 concludes.

\section{Economic Mechanism}

\subsection{The Concept of Task-Specific Human Capital}

This section defines how occupations are related to each other and introduces our concept of taskspecific human capital. We assume that output in an occupation is produced by combining multiple tasks, for example negotiating, teaching or managing personnel. These tasks are general in the sense that they are productive in different occupations. Occupations differ in which tasks they require and in the relative importance of each task for production. An individual's productivity is then 'specific' to that occupation to the extent that occupations place different values on combinations of skills.

More specifically, consider the case of two tasks, denoted by $j=A, M$. We think of them as manual and analytical tasks. Workers are endowed with a productivity in each task, which we denote by $T_{i t}^{j}, j=A, M$. Occupations combine the two tasks in different ways. For example, one occupation might rely heavily on analytical tasks, a second more on manual tasks, and a third combines the two in equal proportion. Let $\beta_{o}\left(0 \leq \beta_{o} \leq 1\right)$ be the relative weight on the analytical task, and $\left(1-\beta_{o}\right)$ be the relative weight on the manual task. We specify worker $i$ 's productivity (measured in log units) in occupation $o$ as

$$
\ln S_{i t}=\beta_{o} T_{i t}^{A}+\left(1-\beta_{o}\right) T_{i t}^{M} .
$$

For example, if in an occupation analytical tasks are more important than manual tasks, $\beta_{o}>0.5$. In another occupation, only the manual task might be performed, so $\beta_{o}=0$. By restricting the weights on 
the tasks to sum to one, we focus on the relative importance of each task, not on the task intensity of an occupation. We impose this restriction for illustrative purposes, as it simplifies the notation. None of our empirical results below however require this restriction.

In this framework, we can define the relation between occupations in a straightforward way. Two occupations $o$ and $o^{\prime}$ are similar if they employ analytical and manual tasks in similar proportions, i.e. $\beta_{o}$ is close to $\beta_{o^{\prime}}$. We can then measure the distance between the two occupations as the absolute difference between the weight given to the analytic task in each occupation, i.e. $\left|\beta_{o}-\beta_{o^{\prime}}\right|$. In this setup, the occupation that fully specializes in the analytical task $\left(\beta_{o}=1\right)$ and the one that fully specializes in the manual task $\left(\beta_{o}=0\right)$ are the two most distant occupations; the distance between these two occupations is equal to one.

We assume that log-productivity can be decomposed into a time-varying component that captures human capital accumulation, $X_{i o t} \gamma_{o}$, and a time-invariant component that captures the quality of the occupational match, $\beta_{o} T_{i}^{A}+\left(1-\beta_{o}\right) T_{i}^{M}$ :

$$
\ln S_{\text {iot }}=\underbrace{\gamma_{o} X_{i o t}}_{\text {Human Capital }}+\underbrace{\beta_{o} T_{i}^{A}+\left(1-\beta_{o}\right) T_{i}^{M}}_{\text {Match Quality }}
$$

We now describe each component in turn.

Human Capital Accumulation With time in the labor market, individuals become more productive in each task through learning-by-doing. In particular, we assume that $X_{\text {iot }}$ contains three types of human capital: general human capital $\left(E x p_{i t}\right)$, purely occupation-specific human capital $\left(O T_{i t}\right)$, and what we call task-specific human capital $\left(T T_{i t}\right)$. The vector $\gamma_{o}=\left[\begin{array}{lll}\gamma_{1 o} & \gamma_{2 o} & \gamma_{3 o}\end{array}\right]$ denotes the return to the three types of human capital. Note that the returns to the three types of human capital vary by occupation-i.e. occupations differ in the value placed on general, task- and occupation-specific human capital respectively.

General human capital is valuable in all occupations, while occupation-specific human capital is 
fully lost once a worker leaves the occupation. Task-specific human capital in contrast is transferable to occupations with similar skill requirements but less so to those that use very different tasks. ${ }^{5}$ More specifically, we assume that the transferability of skills between the source and destination occupation depends on the distance between the two occupations: Workers can transfer a fraction $1-\left|\beta_{o}-\beta_{o^{\prime}}\right|$ of their human capital if they switch from occupation $o$ to $o^{\prime}$. For example, if workers move from an occupation that fully specializes in the analytical task $\left(\beta_{o}=1\right)$ to an occupation that fully specializes in the manual task $\left(\beta_{o^{\prime}}=0\right)$, none of the acquired skills can be transferred. If, in contrast, workers move from an occupation that mostly uses the analytical task (e.g. $\beta_{o}=0.75$ ) to an occupation that employs both tasks in equal proportions (e.g. $\left.\beta_{o^{\prime}}=0.5\right)$, they are able to transfer 75 percent of their acquired skills. Consequently, task-specific human capital is neither fully general nor purely specific, but partially transferable across occupations. ${ }^{6}$

These assumptions allow us to collapse the accumulation of skills in multiple tasks into a onedimensional observable measure of task-specific human capital, $T T_{i t}$. In particular, these assumptions imply that task-specific human capital evolves according to $T T_{i t+1}=1+T T_{i t}$ for occupational stayers and $T T_{i t+1}=1+\sum_{s=1}^{t} \sum_{o^{\prime}=1}^{O}\left(1-\left|\beta_{o}-\beta_{o^{\prime}}\right|\right) * D_{i o^{\prime} s}$ for occupational switchers where $o$ denotes the workers' current and $o^{\prime}$ the sequence of past occupations. $D_{i o^{\prime} s}$ in turn is an indicator equal to one if individual $i$ worked in occupation $o^{\prime}$ in period $s$ and zero otherwise. Hence, task human capital is calculated from occupation tenure in all previous occupations inversely weighted by the distance between the current and previous occupations.

Match Quality The occupation-specific match component is specified as a weighted average of the individual's productivity in each task, $\beta_{o} T_{i}^{A}+\left(1-\beta_{o}\right) T_{i}^{M}$. This differs from existing models of occupational choice, such as Neal (1999) and Pavan (2005), which assume, in line with the assumption

\footnotetext{
${ }^{5}$ Our definition of task-specific human capital differs from that by Gibbons and Waldman (2006). In their setup, task human capital is specific to the job within a firm and might therefore not be transferable across jobs within the same firm.

${ }^{6}$ A more general model of occupational choice and human capital accumulation would allow workers to invest separately in task-specific skills $A$ and $M$. For instance, learning a task could depend on the usage of a task in an occupation. If a worker chooses an occupation that mainly specializes in task $A$, he would mainly accumulate skills in task $A$. This ties the skill investment decision to the choice of an occupation. See Murphy (1986) or Rosen (1983) for models along these lines. However, this more general model would not lead to an empirical specification we can estimate with our data.
} 
that specific skills fully depreciate upon an occupation switch, that the occupational match is uncorrelated across occupations. In our specification, in contrast, the correlation between the match quality in two occupations depends on the distance between the occupations-which is in line with our concept of task-specific skills.

\subsection{Wage Determination and Occupational Mobility}

Wages in occupation $o$ and time $t$ are equal to worker $i$ 's productivity, $S_{i o t}$, multiplied with the occupation-specific skill price, $P_{o}$, i.e. $w_{i o t}=P_{o} S_{i o t}$. Hence, log-wages satisfy:

$$
\begin{aligned}
\ln w_{i o t} & =p_{o}+\ln S_{i o t}+\varepsilon_{i o t}=p_{o}+\gamma_{o} X_{i o t}+\beta_{o} T_{i}^{A}+\left(1-\beta_{o}\right) T_{i}^{M}+\varepsilon_{i o t} \\
& =\underbrace{p_{o}+\gamma_{1 o} E x p_{i t}+\gamma_{2 o} O T_{i o t}+\gamma_{3 o} T T_{i t}}_{\text {observed }}+\underbrace{\beta_{o} T_{i}^{A}+\left(1-\beta_{o}\right) T_{i}^{M}+\varepsilon_{i o t}}_{\text {unobserved }}
\end{aligned}
$$

where $p_{o}=\ln P_{o}$. We have added an iid error term $\varepsilon_{i o t}$ is assumed to be uncorrelated with the regressors and reflects for instance measurement error in wages. We observe general $\left(\operatorname{Exp}_{i t}\right)$, occupation-specific $\left(O T_{i o t}\right)$, and task-specific skills $\left(T T_{i t}\right)$. We do not observe the quality of the match, $\beta_{o} T_{i}^{A}+\left(1-\beta_{o}\right) T_{i}^{M}$. Since the concept of task-specific human capital is novel, we next clarify the interpretation of the return to task-specific human capital, $\gamma_{2 o}$. Consider a worker who has worked for his occupation $o$ for one year. Suppose he is exogenously displaced from his occupation and then randomly assigned to a new occupation. A worker who moves to the most similar occupation loses $\gamma_{2 o}$ (i.e. the purely occupationspecific skills). In contrast, a worker who moves to the most distant occupation loses $\gamma_{2 o}+\gamma_{3 o}$, while a worker who moves to an occupation where he can transfer fifty percent of his skills loses $\gamma_{2 o}+0.5 \gamma_{3 o}$.

Of course, workers are not randomly allocated into occupations. We assume that workers search over occupations to maximize earnings. In one extreme, as for instance in Miller (1984), Neal (1999) and Pavan (2005), the search process is purely undirected, i.e. the probability of receiving an offer from an occupation is the same across all workers and all occupations, regardless of the worker's productivity in each task. In the opposite extreme, workers know the location of their best match already at labor 
market entry, and find employment in this occupation. In this case (and in the absence of productivity shocks), workers would never switch occupations. The reality is probably somewhere in between. In order to ensure that there is some occupational mobility in our set-up, we rule out the second extreme case. However, we do not require assumptions about how exactly the search process looks like: search may be either purely undirected or (partially) directed. For Germany, Fitzenberger and Kunze (2006) and Fitzenberger and Spitz-Öner (2005) argue that search mobility is the most important source of occupational switches.

The decision to switch occupations is then determined by three factors: the potential loss in occupation- and task-specific human capital $\left(O T_{i o t}, T T_{i t}\right)$, the task match $\left(\beta_{o} T_{i}^{A}+\left(1-\beta_{o}\right) T_{i}^{M}\right)$ and the occupation-specific returns to human capital $\left(\gamma_{1 o}, \gamma_{2 o}, \gamma_{3 o}\right.$ and $\left.p_{o}\right)$. If returns to skills are the same across occupations, workers are willing to switch occupations only if the gain in match quality compensates for the loss in occupation- and task-specific human capital. If, in contrast, the returns to human capital accumulation in the prospective occupation exceed those in the current occupation, workers may voluntarily switch occupations even if they lose specific human capital and are worse matched in the new occupation. This is because the new occupation promises higher wage growth in the future than the old one.

Our framework produces a number of novel empirical implications. It implies that, everything else equal, workers are more likely to move to occupations in which they can perform similar tasks as in their previous occupation. The reason is that task-specific human capital is more valuable in similar than in distant occupations. We also expect that distant moves (i.e. moves to occupations with $\beta_{o}$ very different from the current occupation) occur early, rather than late, in the labor market career. This is so for two reasons. First, the accumulation of task-specific human capital makes distant occupational switches increasingly costly. Second, with time in the labor market, workers gradually locate better and better occupational matches. It therefore becomes less and less likely that they accept offers from very distant occupations-even if they do not accumulate task-specific human capital in the labor market. Since the transferability of task-specific human capital as well as the correlation of the match quality across 
occupations depends on the occupational distance, we also expect that wages at the source occupation are a better predictor for wages at the target occupation if the two occupations require similar tasks. A further advantage of our framework is that allows us to quantify the importance of task-specific human capital for individual wage growth, relative to general and occupation-specific human capital.

\subsection{Comparison with Alternative Approaches}

Our setup is closely related to the Roy model of occupational sorting (Roy, 1951; Heckman and Sedlacek, 1985). Just like in the Roy model, individuals in our framework sort themselves into occupations according to comparative advantage. While the original Roy model allows skills to be arbitrarily corre-

lated across occupations, we impose a linear factor structure with two factors $\left(\beta_{o} T_{i t}^{A}+\left(1-\beta_{o}\right) T_{i t}^{M}\right)$. This restriction allows us to define how similar occupations are in their skill requirements in a straightforward way. In addition, our framework also incorporates search over occupations into the Roy model.

The framework outlined here is also related to search and matching models of the labor market (Jovanovic, 1979a; 1979b). As in search or matching models, our setup includes a match component that (partially) determines mobility decisions. Whereas search and matching models assume that specific skills are fully lost upon an occupation switch and that match qualities uncorrelated across occupations, our set-up also allows for a partial transferability of specific skills and a correlation of match qualities across occupations, depending on the occupational distance. This does not only provide new insights into the direction of occupational mobility, but also allows us to analyze the importance of task-specific human capital for individual wage growth relative to other forms of human capital.

In a recent paper, Lazear (2003) also sets up a model in which firms use general skills in different combinations with firm-specific weights attached to them. In this model, workers are exogenously assigned to a firm (in our application: occupation) and then choose how much to invest in each skill. Our - in our opinion more intuitive - approach assumes instead that workers are endowed with a productivity in each task, and then choose the occupation. Furthermore, unlike Lazear (2003), our empirical analyses focus on the transferability of skills across occupations and its implications for occupational mobility 
and individual wage growth.

\section{Data Sources and Descriptive Evidence}

To study the transferability of skills empirically, we combine two different data sources from Germany. Further details on the definition of variables and sample construction can be found in Appendix A.

\subsection{Data on Tasks Performed in Occupations}

Our first data set contains detailed information on tasks performed in occupations, which we use to characterize how similar occupations are in their skill requirements. The data come from the repeated cross-section German Qualification and Career Survey, which is conducted jointly by the Federal Institute for Vocational Education and Training (BIBB) and the Institute for Employment (IAB) to track skill requirements of occupations. The survey, previously used for example by DiNardo and Pischke (1997) and Borghans et al. (2006), is available for four different years: 1979, 1985, 1991/92 and 1998/99. Each wave contains information from 30,000 employees between the ages of 16 and 65 . In what follows, we restrict our analysis to men since men and women differ significantly in their work attachments and occupational choices.

In the survey, individuals are asked whether they perform any of nineteen different tasks in their job. Tasks vary from repairing and cleaning to buying and selling, teaching, and planning. For each respondent, we know whether he performs a certain task in his job and whether this is his main activity. Table 1 lists the fraction of workers performing each of the nineteen different tasks. Following Autor et al. (2003) and Spitz-Öner (2006), we combine the 19 tasks into three aggregate groups: analytical tasks, manual tasks and interactive tasks. On average, 55 percent report performing analytic tasks, 72 percent manual tasks, and 49 percent interactive tasks. The picture for the main task used is similar: 32 percent report analytical tasks, 57 percent manual tasks and 28 percent interactive tasks as their main activity on the job.

The last two columns in Table 1 show the distribution of tasks performed on the job for two popular 
occupations: teacher and baker. According to our task data, a teacher primarily performs interactive tasks (95.3 percent) with teaching and training others being by far the most important one (91.4 percent). Two other important tasks are correcting texts or data (39.6 percent) and organize, coordinate, manage personnel (39.4 percent). A baker in contrast is a primarily manual occupation (96.4 percent) with manufacturing, producing, installing as the most important task (87.9 percent) followed by teaching and training others (34.3 percent) as well as organizing, coordinating and managing personnel (29.9 percent).

To see how task usage varies across the 64 occupations contained in our data, Table A1 lists the fraction of workers performing manual, analytical, and interactive tasks for all 64 occupations. The table shows that there is a lot of variation in task usage across occupations. For example, while the average use of analytical tasks is 56.3 percent, the mean varies from 16.7 percent as an unskilled construction worker to 92.4 percent for an accountant. We checked whether tasks performed in the same occupation vary across industries and found little support for this conjecture. This results suggest that industries matter little for measuring human capital once we control for the skill set of an occupation, and justifies our focus on occupations.

\subsection{Measuring the Distance between Occupations}

According to our framework, two occupations have similar skill requirements if they put similar weights on tasks, i.e. individuals perform the same set of tasks. With two tasks, the maximum distance between two occupations occurs if occupation o only uses task $A\left(\beta_{o}=1\right)$, and occupation o/ only task $M\left(\beta_{o^{\prime}}=0\right)$. The basic idea extends naturally to the case with more than two tasks. Though we cannot observe these weights directly, our task data provide us with a closely related measure of the skill content of each occupation.

In particular, the task data described in the previous section tell us the set of skills employed in each occupation. We can then characterize the skill content of each occupation by a 19-dimensional vector $q_{o}=\left(q_{o 1}, \ldots, q_{o J}\right)$ where $q_{o j}$ denotes the fraction of workers in an occupation performing task $j$. 
We can think of this vector as describing a position in the task space. In equilibrium, an occupation with a high weight $\beta_{o j}$ for a particular task will also employ this task extensively, i.e. have a high $q_{o j}$. To measure the distance between occupations in the task space, we use the angular separation or uncentered correlation of the vectors $q_{o}$ and $q_{o^{\prime}}$ :

$$
\operatorname{AngSep}_{o o^{\prime}}=\frac{\sum_{j=1}^{J} q_{j o} * q_{j o^{\prime}}}{\left[\left(\sum_{j=1}^{J} q_{j o}^{2}\right) *\left(\sum_{k=1}^{J} q_{k o^{\prime}}^{2}\right)\right]^{1 / 2}}
$$

where $q_{j o}$ is the fraction of workers using task $j$ in occupation $o$ and $q_{j o^{\prime}}$ is defined analogously. This measure defines the distance between two occupations as the cosine angle between their positions in vector space. The measure has been used extensively in the innovation literature to characterize the proximity of firms' technologies (Jaffe, 1986). ${ }^{7}$

We use a slightly modified version of the above, namely $D i s_{o o^{\prime}}=1-A n g S e p_{o o^{\prime}}$ as our distance measure. The measure varies between zero and one. It is zero for occupations that use identical skill sets and unity if two occupations use completely different skills sets. The measure will be closer to zero the more two occupations overlap in their skill requirements. To account for changes in task usage over time, we calculated the distance measures separately for each wave. For the years 1975-1982, we use the measures from the 1979 cross-section, for 1983-1988 the task measures from the 1985 wave; for the years 1989-1994, we use the measures based on the 1991/2 wave; and the $1997 / 8$ wave for the years 1995-2001. While there have been changes over time in the distance measures, they are with 0.7 highly correlated. Our results are robust to assigning different time windows to the measures.

The mean distance between occupations in our data is 0.24 with a standard deviation of 0.22 (see Table 2). The most similar occupational move is between paper and pulp processing and a printer or typesetter with a distance of 0.002 . The most distant move is between a banker and an unskilled

\footnotetext{
${ }^{7}$ Unlike the Euclidean distance, the angular separation measure is not sensitive to the length of the vector, i.e. whether an occupation only uses some tasks but not others. For example, two occupations using all tasks moderately (and thus have a position close to the origin of the coordinate system) will be similar according to the angular separation measure even if their task vectors are orthogonal, and therefore distant according to the Euclidean distance measure. If all vectors have the same length (i.e. if all tasks are used by at least some workers in all occupations), our measure is proportional to the Euclidean distance measure.
} 
construction worker. Table 2 also shows at the bottom the distance measure for the three most common occupational switches separately by education group. The most popular move for low-skilled worker is between a truck driver and a warehouse keeper, while for the high skilled, it is between an engineering occupation and a chemist or physicist. ${ }^{8}$

\subsection{The German Employee Panel}

Our second data set is a two percent sample of administrative social security records in Germany from 1975 to 2001 with complete job histories and wage information for more than 100,000 employees. The data has at least three advantages over household surveys commonly used in the literature to study mobility in the United States. First, its administrative nature ensures that we observe the exact date of a job change and the wage associated with each job. Second, measurement error in earnings and occupational titles are much less of a problem than in typical survey data as misreporting is subject to severe penalties. Finally, occupational titles are consistent across firms as they form the basis for wage bargaining between unions and employers.

The data is representative of all individuals covered by the social security system, roughly 80 percent of the German workforce. It excludes the self-employed, civil servants, and individuals currently doing their compulsory military service. As in many administrative data sets, our data is right-censored at the highest level of earnings that are subject to social security contributions. Top-coding is negligible for unskilled workers and those with an apprenticeship, but reaches almost 25 percent for university graduates. For the high-skilled, we use tobit or semiparametric methods to account for censoring.

Since the level and structure of wages differs substantially between East and West Germany, we drop from our sample all workers who were ever employed in East Germany. We also drop all those working in agriculture. In addition, we restrict the sample to men who entered the labor market in or after 1975. This allows us to construct precise measures of actual experience, firm, task, and occupation tenure

\footnotetext{
${ }^{8}$ Our distance measure treats all tasks symmetrically. It may, however, be argued that some tasks are more similar than others. For instance, the task 'equipping machines' may be more similar to 'repairing' than to 'teaching'. In order to account for this, we also defined the angular separation measure using information on the 3 aggregate task groups (analytical, manual and interactive tasks). The results based on this alternative distance measures are qualitatively very similar to the ones reported in the paper.
} 
from labor market entry onwards. Labor market experience and our tenure variables are all measured in years and exclude periods of unemployment and apprenticeship training.

Since the concept is novel, we now explain how we calculate our measure of task human capital. Each individual starts with zero task tenure at the beginning of his career. Task tenure increases by the duration of the spell if a worker remains in the same occupation. If he switches occupations, we calculate task tenure in the new occupation as the weighted sum of time spent in all previous occupations where the weights are the distance between the current and all past occupations. ${ }^{9}$

As an example, consider a person who starts out in occupation A, then switches to occupation B after one year, and switches to occupation $\mathrm{C}$ again after one year. Suppose the distance between occupation A and B is 0.5 , between occupation A and C 0.2 and 0.8 between occupation B and C. Before moving to occupation B, he has accumulated 1 unit of task tenure. Since he can only transfer 50 percent of his task human capital to occupation B, his task tenure declines to 0.5. After working one year in occupation B, he accumulates another unit of task human capital, so task tenure increases to $1.5(0.5 * 1+1)$. Switching to occupation $\mathrm{C}$ after the second year, the worker can transfer 20 percent of his task human capital he accumulated in occupation $\mathrm{A}$ in the first period and 80 percent of the human capital accumulated in occupation B in the second period. His task tenure variables is thus $1=$ $0.2 * 1+0.8 * 1$

Table 3 reports summary statistics for the main variables. In our sample, about 16 percent are low-skilled workers with no vocational degree. The largest fraction (68.3 percent) are medium-skilled workers with a vocational degree (apprenticeship). The remaining 15.4 percent are high-skilled workers with a tertiary degree from a technical college or university. Wages are measured per day and deflated to 1995 German Marks. Mean task tenure in our sample is between 4.6 years for the low-skilled and 4.8 years for the medium-skilled. Total labor market experience is on average a year higher (since the general skills captured by time spent in the labor market do not depreciate) and about one year lower

\footnotetext{
${ }^{9}$ In principle, our separation measure takes values between 0 and 1 . However, the maximum distance observed in our data (across all occupation pairs) is 0.93. In our calculation, we assume that a worker cannot transfer any skills if he makes the most distant occupation switch, and define the relative distance between two occupations $\mathrm{A}$ and $\mathrm{B}$ as the difference between the maximum distance in our data and the distance between occupations $\mathrm{A}$ and $\mathrm{B}$, divided by the maximum distance. Our results do not change if we use the actual distance instead of this relative distance measure.
} 
for occupation tenure (since this measure assumes that these skills fully depreciate with an occupational switch).

Occupational mobility is important in our sample: 19 percent of the low-skilled switch occupations each year and with 11 percent somewhat lower for the high skilled. To see how occupational mobility varies over the career, Figure 1 plots quarterly mobility rates over the first ten years in the labor market, separately by education group. Occupational mobility rates are very high in the first year (particularly in the first quarter) of a career, and highest for the low-skilled. Ten years into the labor market, quarterly mobility rates drop to 2 percent. The next section uses our distance measure to analyze in more detail the type of occupational mobility we observe in the data.

\section{Patterns in Occupational Mobility and Wages}

We now use the sample of occupational movers to demonstrate that skills are partially transferable across occupations. Section 4.1 studies mobility behavior, while Section 4.2 analyzes wages before and after an occupational move.

\subsection{Occupational Moves are Similar}

Our framework predicts that workers are more likely to move to occupations with similar tasks requirements. In contrast, if skills are either fully general or fully specific to an occupation, they do not influence the direction of occupational mobility: in the first case, human capital can be equally transferred to all occupations, while in the second case, human capital fully depreciates irrespective of the target occupation.

To test this hypothesis, we compare the distance of observed moves to the distribution of occupational moves we would observe if the direction of occupational moves was random. In particular, we assume that under random mobility the decision to move to a particular occupation is solely determined by its relative size. For example, if occupation A employs twice as many workers as occupation B, the probability that a worker joins occupation A would then be twice as high as the probability that he 
joins occupation B.

Observed moves are calculated as the percentage of moves for each value of the distance measure. To compare this to expected distance under random mobility, we calculate the fraction of individuals leaving an occupation that would end up in any of the 63 occupations in proportion to their relative size. Each random source-target occupation combination is then multiplied with the appropriate distance measure. The way we calculate random mobility ensures that we account for shifts in the occupational structure over time, i.e. the fact that employment shares may be increasing or decreasing for some occupations.

Figure 2 plots the density of the distance measure under observed and random mobility. The horizontal axis is the distance measure where larger values are associated with movements to more distant occupations. The distribution under both random and observed mobility is bimodal, with many occupation switches concentrated at the distance measure of about 0.1 and 0.65 . The peak at the distance measure of 0.1 is considerably lower, while the share of distant occupation switches is considerably higher under random than under observed mobility. Therefore, observed moves are much more similar than we would expect if occupational mobility was determined by relative size alone. The two distributions are statistically different at the 1 percent level based on a Kolmogoroff-Smirnov test. To allow a more detailed comparison, Table 2 compares selected moments of the distribution of our distance measure under observed and random mobility. The observed mean and the 10th, 25th, 50th, 75th and 90th percentile of the distance distribution are much lower than what we would observe under random mobility.

Our framework also predicts that distant moves occur early in the labor market career and moves become increasingly similar with time in the labor market. One reason is that the accumulation of task-specific skills makes distant occupational switches increasingly costly. A second reason is that with time in the labor market, workers gradually locate better and better occupational matches. It therefore becomes less and less likely that they accept offers from very distant occupations.

Table 5 provides empirical support for these predictions. It shows the results from a linear regression where the dependent variable is the distance of an observed move separately by education group. Column 
(1) controls for experience and experience squared and year and occupation dummies. For all education groups, the distance of an occupational move declines with time spent in the labor market though at a decreasing rate. The declining effect is strongest for the high-skilled, who also make more similar moves on average (see last row). For the high-skilled, 10 years in the labor market decrease the distance of a move by 0.16 or about 70 percent of the standard deviation. For the medium-skilled, the decline is only about 0.030 or 14 percent of a standard deviation.

Column (2) adds the time spent in the last occupation, while column (3) reports the results from an fixed-effects estimator to account for heterogeneity in mobility behavior across individuals. More time spent in the previous occupation decreases the distance of an occupational move in addition to labor market experience. The within estimator shows that occupational moves become more similar even for the same individual. The results are therefore not driven differences between low- and high-experience workers. In fact, the decline in the distance becomes even more pronounced for all education groups in the fixed effects estimation.

Table 4 imposed a quadratic relationship between actual labor market experience and the distance of moves. In Figure 3, we relax this restriction. The figure displays the average distance of a move by actual experience, separately for the three education groups. The average distance is obtained from a least-squares regression of the distance on dummies for actual experience as well as occupation and year dummies, similar to Column (1) in Table 4. The figure shows that occupational moves become more similar with time in the labor market for all education groups, but particularly so for the high-skilled. For this education group, the decline is particularly pronounced in the first 5 years in the labor market. The decline between the first and 15th year of actual labor market experience is statistically significant at the 1 percent level for all education groups.

In sum, individuals are more likely to move to occupations in which similar tasks are performed as in their source occupation, particularly so later in their career. Our framework proposes a simple explanation for this pattern. The basic mechanism is that human capital is more transferable between occupations with similar skill requirements. 


\subsection{Wages in Current Occupation Depend on Distance of Move}

If skills (i.e. those accumulated in the labor market, $T T_{i o t}$, as well as those workers bring to the labor market, $\left.\beta_{o} T_{i t}^{A}+\left(1-\beta_{o}\right) T_{i t}^{M}\right)$ are partially transferable between occupations using similar skills, we would expect wages at the source occupation to be a better predictor for wages at a similar target occupation. This implies that the correlation of wages before and after an occupational move should decline in the distance of a move. Table 6 investigates this hypothesis. It reports estimates from a wage regression where the dependent variable is the log daily wage. All specifications include experience and experience squared as well as year and occupation dummies. Results are reported separately by education. As a benchmark for comparison, the first specification (column (1)) estimates the correlation of wages for occupational stayers. Wages in the same occupation are highly correlated over time with the correlation being strongest for university graduates.

In the next specification, we restrict the sample to occupational movers who start out with zero occupational tenure (column (2)). For all education groups, the correlation of wages is lower among occupational movers than among occupational stayers. Specification 3 analyzes whether the impact of wages in the source occupation on wages in the target occupation varies with the distance of the occupational move. We add the distance of the move as well as the distance interacted with the wage at the source occupation as additional regressors. Indeed, the predictive power of the wage at the source occupation is larger for movers to similar occupations. Interestingly, the difference in the correlation is strongest for the high-skilled workers, i.e. the group that is also most likely to move to similar occupations. For this education group, our estimates imply that the impact of the wage at the source occupation on the wage at the target occupation is 0.35 for the most similar move, 0.31 for the median move $(0.351-0.103 \times 0.354)$, and approaches 0 for the most distant move $(0.352-0.939 \times 0.354)$.

As a second test of skill transferability, we estimate whether tenure in the previous occupation matters for wages in the new occupation. In Column (1) of Table 7, we regress wages at the new occupation on occupational tenure at the previous occupation and the same controls as in Table 6 . Past occupational tenure positively affects wages at the new occupation. This result is consistent with 
previous evidence that post-displacement wages depend positively on tenure in the pre-displacement job (e.g. Kletzer, 1989). Column (2) adds the distance measure interacted with past occupational tenure as controls. As expected, the predictive power of past occupational tenure is stronger if source and target occupations are similar. In line with our previous results, the impact of past occupational tenure declines more sharply with distance for university graduates. For this education group, the impact of past occupational tenure is 2.3 percent for the most similar move, but only 1 percent $(0.023-0.103 \times$ $0.072=0.010)$ for the median move.

Figure 4a relaxes the assumption that the correlation between wages across occupations declines linearly with the distance. The $\mathrm{x}$-axis shows the distance with one being the most similar occupational moves and 10 the most distant ones, while the y-axis reports the coefficient on the wage in the source occupation for each of the 10 categories. The coefficient is obtained form a OLS regression (tobit regression for the high-skilled) that controls for actual experience, actual experience squared, year dummies, the wage at the source occupation, 9 dummies for the distance of the move and the 9 dummies interacted with the wage at the source occupation (see column (3) in Table 6). Two things are noteworthy: first, the figure highlights that wages at the source occupation have a stronger explanatory power for the wage at the target occupation if the source and the target occupation have similar skill requirements. Second and in line with our results on mobility and wages, the decline is strongest for the high-skilled. For this education group, the partial correlation coefficient between wages in the source and target occupation drops from 37 percent for the 10 percent most similar moves to around 15 percent for the 10 percent most distant moves. The drop is statistically significant at a one percent level for all education groups.

Figure $4 \mathrm{~b}$ provides a similar analysis for past occupational tenure. The y-axis are now the coefficients on the 9 distance measure dummies from a tobit regression that also controls for actual experience, actual experience squared and year dummies. The correlation between past occupational tenure and wages in the new occupations is declining roughly linearly with the distance of the move. As before, the declining pattern is strongest for the high-skilled, particularly for very distant occupational moves.

We have performed a number of robustness checks. First, results for alternative distance measures 
are very similar. Second, our sample of movers contains both occupational switches between firms as well as within the same firm. The latter account for roughly 10 percent of all occupational movers. If some skills are tied to a firm, internal movers would have more portable skills than firm switchers. We therefore reestimated our specifications in Table 5, 6 and 7 using only external movers. The results exhibit the same patterns in mobility and wages which we observe for the whole sample of movers. Finally, our original sample of movers contains everybody switching occupations irrespective of the duration of intermediate un- or nonemployment spells. To the extent that those remaining out of employment for an extended period of time are different from for example job-to-job movers, our results might not be valid for those with high attachments to the labor market. To account for this, we reestimated the results only for the sample of workers with intermediate un- or nonemployment spells of less than a year. Again, this does not change the patterns on mobility and wages.

\subsection{Can these Patterns be Explained by Unobserved Heterogeneity?}

The strong patterns in mobility and wages reported in the last section support our view that human capital accumulated in the labor market is portable across occupations, and the more so the more similar are the occupations. This section discusses whether our findings could be rationalized by individual heterogeneity. Note first that all results presented above are based on a sample of occupational movers. The patterns in mobility and wages can therefore not be accounted for by a simple mover-stayer model, where movers have a higher probability of leaving a job and therefore lower productivity because of less investment in specific skills. To the extent that movers differ from stayers in terms of observable and unobservable characteristics, this sample restriction reduces selection bias.

However, other sources of unobserved heterogeneity could bias our results. First, one might argue that the similar moves in the data are voluntary transitions, while distant moves occur because of layoffs from the previous job. If wages at the source and target occupation are more strongly correlated after a quit than after a layoff, then the distinction between quits and layoffs can explain why wages are more highly correlated across similar occupations. It would also explain why past occupational tenure has 
a higher return in a similar occupation. However, the distinction between voluntary and involuntary movers does not explain why voluntary movers move to similar occupations in the first place. While we cannot directly distinguish between voluntary and involuntary job changes, we checked whether our results differ between job-to-job and job-to-unemployment transitions. Job-to-job changes are more likely to be voluntary, while moves into registered unemployment are more likely to be involuntary. We find that patterns in occupational mobility are similar for the two types of moves. This results makes it unlikely that voluntary and involuntary occupational moves are responsible for our findings.

Second, suppose that the sample of movers differs in their taste for particular tasks. Some individuals prefer research over negotiating, while other prefer negotiating over managing personnel etc. Taste heterogeneity can explain why we see similar moves in the data. If individuals choose their occupations based on earnings and preferences for tasks, individuals would want to move to occupations with similar task requirements. However, a story based on taste heterogeneity alone cannot explain why wages are more strongly correlated between similar occupations. If there are compensating wage differentials, we would actually expect the opposite: individuals would be willing to accept lower wages for a move to an occupation with their preferred task requirements.

Finally, suppose that high ability workers are less likely to switch occupations. This could account for the fact that the time spent in the last occupation has a positive effect on wages in the current occupation, as past occupational tenure would act as a proxy for unobserved ability in the wage regression (see Table 7). However, unobserved ability per se cannot explain why the effect of past occupational tenure should vary with the distance of the move or why individuals move to similar occupations at all.

This discussion highlights that a simple story of unobserved heterogeneity cannot account for all of the results presented above. Our theoretical framework however also makes clear that occupational movers are not a random sample of the population of workers. Individuals choose to switch occupations and they can also choose the distance of their occupational move. The next section outlines an estimation approach to quantify the importance of task-specific human capital for individual wage growth that accounts for the endogeneity of occupational mobility. 


\section{Task-Specific Human Capital and Individual Wage Growth}

To estimate the contribution of task-specific human capital to individual wage growth, we start from the log-wage regression (equation (1) in Section 2) augmented by control variables $\widetilde{X}_{\text {iot }}$ :

$$
\begin{aligned}
\ln w_{i o t} & =\gamma_{1 o} \operatorname{Exp}_{i t}+\gamma_{2 o} O T_{i o t}+\gamma_{3 o} T T_{i o t}+\eta^{\prime} \tilde{X}_{i o t}+u_{i o t} \\
u_{i o t} & =\beta_{o} T_{i}^{A}+\left(1-\beta_{o}\right) T_{i}^{M}+\varepsilon_{i o t}
\end{aligned}
$$

Here $\operatorname{Exp}_{i t}$ denotes actual experience, $O T_{i o t}$ occupation tenure, and $T T_{i o t}$ task tenure, capturing general, occupation- and task-specific human capital accumulation respectively. $\gamma_{1 o}, \gamma_{2 o}, \gamma_{3 o}$ denote the

occupation-specific return to the three types of human capital. $\widetilde{X}_{i o t}$ captures other control variables (year, occupation and region dummies) with the common return $\eta$. The unobserved (for the econometrician) error term $u_{i o t}$ consists of the task-specific match in an occupation $\left(\beta_{o} T_{i}^{A}+\left(1-\beta_{o}\right) T_{i}^{M}\right)$ and an iid error term $\left(\varepsilon_{i o t}\right)$.

Our goal here is to identify the average return to the three types of human capital across occupations, $\bar{\gamma}_{k o}=E_{o}\left[\gamma_{k o}\right], k=1,2,3$. Rewriting equation (2) as a random coefficient model:

$$
\begin{aligned}
\ln w_{i o t} & =\bar{\gamma}_{1} \operatorname{Exp}_{i t}+\bar{\gamma}_{2} O T_{i o t}+\bar{\gamma}_{3} T T_{i o t}+\eta^{\prime} \widetilde{X}_{i o t}+\widetilde{u}_{i o t}, \\
\widetilde{u}_{i o t} & =\left(\gamma_{1 o}-\bar{\gamma}_{1}\right) \operatorname{Exp}_{i t}+\left(\gamma_{2 o}-\bar{\gamma}_{2}\right) O T_{i t}+\left(\gamma_{3 o}-\bar{\gamma}_{3}\right) T T_{i t}+\beta_{o} T_{i}^{A}+\left(1-\beta_{o}\right) T_{i}^{M}+\varepsilon_{i o t} .
\end{aligned}
$$

The unobserved error term $\widetilde{u}_{\text {iot }}$ now contains an additional term capturing the occupational heterogeneity in the return to the three types of human capital accumulation.

\subsection{Least Squares Results}

We first present least squares estimates of the wage regressions of (3) as our benchmark. To account for censoring in the wages of university graduates, we estimate censored regressions for this group. Columns (1) to (4) in Table 8 reports the results for two different samples: the whole sample of firm movers and 
stayers, and the sample of workers starting a new firm. The first specification (odd columns) displays results from a wage regression that ignores task-specific human capital, while even columns includes task tenure as an additional regressor. If human capital is indeed partially transferable across occupations, we expect that the inclusion of task tenure will lower the estimated return to both occupational tenure and experience. In addition to the variables reported, all regressions include occupation, region, and time dummies.

The results show several interesting patterns. Returns to task tenure are sizeable and exceed those of occupational tenure for all education groups. Based on the estimates for the whole sample, returns to occupational tenure decline by about 20 percent for the two lower educated groups, and about one-third for the high-skilled once we include task tenure. Returns to experience also decline by about 20 percent for the low- and medium-skilled and by about 30 percent for the high-skilled for a worker with ten years of (actual) labor market experience. The patterns are very similar for the sample of workers starting at a new firm, i.e. workers with firm tenure equal to zero, shown in columns (3) and (4). Compared to the full sample, the return to general experience is lower while the returns to occupation and task tenure are higher for all education groups.

Least squares estimates of (3) are likely to be biased for two reasons. First, individuals select into a new occupation based on the value of their task match, $\beta_{o} T_{i}^{A}+\left(1-\beta_{o}\right) T_{i}^{M}$. The second source of bias is that individuals select into occupations based on the returns to their skills $\left(\gamma_{1 o}, \gamma_{2 o}, \gamma_{3 o}\right)$. We would generally expect the average return to experience, $\bar{\gamma}_{1}$, to be upward biased. This is because with time in the labor market, workers find occupations that best use their task productivity through on-the-job search. Hence, the return to experience does not only reflect accumulation of general human capital, but also wage growth due to job search (see also Topel, 1991; Dustmann and Meghir, 2005).

In contrast, the return to occupation- and task-specific human capital, $\bar{\gamma}_{2}$ and $\bar{\gamma}_{3}$, may be upward or downward biased. On the one hand, workers who are well matched are less likely to switch occupations or move to a distant occupation. This implies a positive (partial) correlation between occupation and task tenure and the match quality, and thus to an upward bias in the return to occupation- and task- 
specific human capital. On the other hand, workers may have switched occupations or moved to a distant occupation because they are particularly well matched with the new occupation. Hence, workers with low levels of occupation and task tenure may have particularly high task matches, leading to a downward bias in the return to occupation- and task-specific human capital. However, workers may also move to a new and/or a distant occupation because of a higher return to human capital, which provides another reason why the (partial) correlation between occupation and task tenure and the error term in (3) cannot be signed.

To get an idea of the magnitude of these biases, we next estimate wage regression (3) for a sample of workers who were exogenously displaced from their job due to plant closure (see Gibbons and Katz, 1991; Neal, 1995 and Dustmann and Meghir, 2005 for a similar strategy). ${ }^{10}$ Displaced workers differ from voluntary firm switchers because they are willing to accept a new job offer if its value exceeds the value of unemployment, as opposed to the value of the old job. Displaced workers lose some of their 'search capital', which should lower the upward bias in the return to experience. For the high-skilled, the return to experience is indeed about 25 percent lower in the sample of displaced movers than in the sample of all firm movers, while there is little difference for the other two education groups (Table 8, columns (5) and (6)). This suggests that job search plays a more important role for the high-skilled. Task tenure remains an important source of individual wage growth for all education groups.

Least squares estimates for the return to general, occupation- and task-specific human capital are likely to be biased even for exogenously displaced workers, as workers select into the post-displacement occupation. Next, we outline a control function estimator to get consistent estimates of the wage regression.

\subsection{Control Function Estimates}

To estimate the mean returns to labor market skills in the wage equation, we need to model the conditional mean of the error term in (3) (Heckman and Vytlacil, 1998). Arrange the regressors into

\footnotetext{
${ }^{10}$ Dustmann and Meghir (2005) provide evidence that the assumption of plant closure as an exogenous job loss is reasonable in the German context.
} 
a vector $X_{i o t}^{\prime}=\left[\operatorname{Exp}_{i t} O T e n_{i o t} T T e n_{i o t} \widetilde{X}_{i o t}\right]$ and let $Z_{i o t}$ denote a vector of instruments. We assume that, for a sample of workers who have just switched firms, the following exclusion restriction holds:

$$
E\left[\widetilde{u}_{i o t} \mid X_{i o t}, Z_{i o t}\right]=0
$$

which is equivalent to

$$
\begin{gathered}
E\left[\beta_{o} T_{i}^{A}+\left(1-\beta_{o}\right) T_{i}^{M} \mid X_{i o t}, Z_{i o t}\right]=0, \text { and } \\
E\left[\gamma_{1 o}-\bar{\gamma}_{1} \mid X_{i o t}, Z_{i o t}\right]=E\left[\gamma_{2 o}-\bar{\gamma}_{2} \mid X_{i o t}, Z_{i t}\right]=E\left[\gamma_{3 o}-\bar{\gamma}_{3} \mid X_{i o t}, Z_{i t}\right]=0
\end{gathered}
$$

If the returns to the three types of human capital accumulation were homogenous across occupations, the exclusion restriction (4) would be sufficient to get consistent estimates. Exclusion restriction (5) accounts for the selection into occupations based on the occupation-specific returns to human capital.

As instruments, we require variables that affect the worker's mobility decision (i.e. whether to move to a new occupation as well as whether to move to a similar or distant occupation), but not his wage offer (conditional on all regressors). Our main instruments for experience are age and age squared. To instrument for occupation tenure, we follow Altonji and Shakotko (1987) and Parent (2000) and use the deviation of occupation tenure from its occupation-specific mean as an instrument. This instrument is uncorrelated with the time-invariant task match, $\beta_{o} T_{i}^{A}+\left(1-\beta_{o}\right) T_{i}^{M}$, by construction. Note that within occupations, occupation and task tenure evolve the same. Consequently, the deviation from its occupation-specific mean is exactly the same for occupation and task tenure. We therefore require an additional instrument for task tenure. We use local labor market conditions, in particular the size of occupation and the average distance to other occupations in the same local labor market, as well as both variables interacted with age as additional instruments. ${ }^{11}$ We expect workers to be less likely to switch occupations in a region with more employment opportunities in the same occupation. We also expect workers to be less likely to move to a distant occupation in a region with more employment

\footnotetext{
${ }^{11}$ The average distance, $A D_{r t}$, to other occupations is computed separately for each local labor market $r$ and time period $t$ as follows: $A D_{r t}=\sum_{o^{\prime} \neq o}^{64} \operatorname{Prop}_{r t o^{\prime}} \cdot$ Distance $\left._{o o^{\prime}}\right)$. We define a region as the individual's county (Kreis) of residence as well as all the neighboring counties, corresponding roughly to a 50 mile radius from the individual's home.
} 
opportunities in similar occupations. Since all our specifications include occupation, region and time dummies, the variation we exploit is changes in the occupational structure over time within the same region. If local labor markets are integrated in the national labor market, factor prices are equalized, and local labor market conditions can be excluded from wages (see Adda et al., 2006 for a similar argument).

To implement the estimator, we estimate in a first step the reduced forms for experience, occupational tenure and task tenure and predict the residuals. The second step estimates the log wage equation in (3) including the estimated residuals as well as their interaction with the endogenous regressors. The interactions between the reduced-form residuals and the regressors are the control functions that account for the selection into occupations based on occupation-specific returns. To correct for generated regressor bias, we bootstrap standard errors with 100 replications using the individual as the sampling unit. For the high-skilled, we use the semiparametric estimator proposed by Blundell and Powell (2004) to account for censoring in addition to endogenous regressors. We describe this estimator in detail in Appendix B.

Table 9, columns (1) and (2) report results for a sample of firm switchers. The first stage of our control function estimator is reported in Table A.2 (low- and medium-skilled) and A.3 (high-skilled), while Table A.4 shows the coefficients on the residuals and their interaction with the main regressors. Both the residuals and the residuals interacted with the regressors enter the wage equation significantly, indicating that selection into occupations based on the task match and occupation-specific returns is important.

For all education groups, the control function estimate and the OLS estimate for the displaced sample (Table 8, columns (5) and (6)) yield similar returns to experience for a worker with 10 years of (actual) labor market experience. The return to task tenure however increases considerably when the control function estimator is used, while the return to occupation tenure decreases. In the case of the low- and high-skilled, the return to occupation tenure becomes significantly negative.

In columns (3) and (4), we report control function estimates for our sample of workers who are exogenously displaced from their firm due to plant closure. Note that we are now identified from workers 
who lose their job due to plant closure more than once-since for workers who experienced only one plant closure our instrument for occupation tenure, i.e. the deviation from its occupation-specific mean, is zero. It is therefore not surprising that estimates are considerably more noisy. For the low-skilled, restricting the sample to exogenously displaced workers has little impact on the point estimates, but only the return to experience is statistically significant. For the medium-skilled, the return to experience remains largely unchanged, but the return to task tenure increases and the return to occupation tenure decreases. For the high-skilled, only the return to experience is statistically significant.

\subsection{Economic Interpretation}

What do our estimates imply about the contribution of task-specific human capital accumulation to individual wage growth over the life-cycle? After ten years in the labor market, a typical medium-skilled worker in our sample has accumulated 9.1 years of actual experience, 6.5 years of occupation tenure, and 7.9 years of task tenure. According to the OLS estimates for the displaced sample (Table 8, column (6)), this worker can expect his wages to grow by 9.5 percent $(0.012 \times 7.9)$ due to task-specific human capital, 17.4 percent $\left(0.028 \times 9.1-0.001 \times 9.1^{2}\right)$ due to general human capital and 8.5 percent $(0.013 \times 7.9)$ due to occupation- specific human capital. Control function estimates for the sample of firm switchers (Table 9, column (2)) imply similar a wage growth due to general human capital (18 percent), but a higher wage growth due to task-specific human capital (21.3 percent). Wage growth due to occupation-specific human capital accumulation is slightly negative (-0.65 percent).

Task-specific human capital plays an even more important role for the high-skilled. According to the tobit estimates for the displaced sample, a typical high-skilled worker ${ }^{12}$ can expect his wage to grow because of general, task-specific, and occupation-specific human capital accumulation by 36.2 percent, of which 40 percent are due to task tenure, 14 percent due to occupation tenure, and 47 percent are due to experience. When we base the calculation on the control function estimates for the sample of firm

\footnotetext{
${ }^{12}$ After 10 years in the labor market, a high-skilled worker has accumulated 6.81 years of actual experience, 4.95 years of occupation tenure, and 6.19 years of task tenure. Notice that these numbers a considerably lower than the corresponding ones for the medium-skilled. This is because the high-skilled are more likely to move in and out of the sample than the medium-skilled, possibly because of spells as self-employed or civil servants.
} 
switchers, task-specific human capital accounts for more than 80 percent of the overall wage growth due to human capital accumulation.

Our estimates can also provide insights into the costs of job displacement due to the loss of occupation- and task-specific skills. We base our calculation on the OLS estimates for the displaced sample (Table 8, column (6)). ${ }^{13}$ Since our calculation excludes the loss in task match quality, our wage losses are a lower bound for the true wage loss of job displacement. Consider a high-skilled worker who is displaced after 10 years in his occupation and finds employment in similar occupation (e.g. in the 10th percentile of the distribution of moves). The predicted wage loss of this worker is 12.3 percent, 10.0 percent from occupation-specific skills but only 0.7 percent from task-specific skills. In contrast, if he would move to a distant occupation (e.g. in the 90th percentile of the distribution of moves), he would lose 30.1 percent, 10.0 percent from occupation-specific skills and 20.1 percent $(0.9 \times 0.230)$ from task-human capital. The basic pattern holds for all education and experience groups: wage losses of displacement vary with the type of the occupational move after displacement.

Our estimates also imply that wage losses after displacement are low to the extent that workers are able to find employment in a similar occupation after displacement. For instance, for high-skilled workers who switches occupations following plant closure, the mean observed distance between the preand post-displacement occupation is 0.177 , while it would be 0.466 if he were randomly assigned to an occupation. Hence, for a high-skilled a worker who has been displaced after 10 years in his occupation and moves to a new occupation, the average predicted wage loss due to task-specific human capital is 4.1 percent $(0.177 \times 0.230)$, but would be more than twice as high $(10.7$ percent $)$ if he were randomly allocated to a new occupation.

These calculations show that task-specific skills are important for wage growth and costs of displacement.

\footnotetext{
${ }^{13}$ The OLS specification yields lower estimates for the return to task-specific, and higher estimates for the return to occupation-specific human capital, than the control function estimates in Table 9. Calculations based on this specification may therefore be thought of as conservative estimate for the importance of task-specific human capital.
} 


\subsection{Further Robustness Checks}

Our wage specification (3) does not incorporate job search over firm matches which has been shown to be an additional source of wage growth (e.g. Topel and Ward, 1991; Pavan, 2005; Yamaguchi, 2007b). How would firm matches affect our findings? Neal (1999) proposes a model in which workers search over both firm and occupation matches. He shows that it is optimal for workers to first search for a good occupation match, and then for a good firm match. For a sample of young workers like ours, he then provides empirical support for such a search strategy. Under the two-stage search strategy, our estimates will be little affected by search over firm matches. The reason is that the majority of young workers in our sample has been in the labor market for less than 8 years so their decision whether to switch occupations and to which occupation to move should be predominantly driven by the task match, and not by the firm match.

What if the worker's search strategy does not follow this two-stage rule? Then firm matches provide another reason why in an OLS regression the return to task tenure may be downward biased, although the bias still cannot be signed. This is because some workers may have moved to a distant occupation because of a high firm match, despite a low task match.

As a robustness check, we estimate first difference regressions, using a sample of firm switchers. ${ }^{14}$ Due to censoring, we cannot estimate first differences for university graduates. Instead, we use Honoré's trimming estimator (1992) for the censored regression (Type 1 tobit model) with fixed effects. Since the estimator is semiparametric, no functional form assumption on the error term is required. However, we do require pairwise exchangeability of the error terms conditional on the included regressors, see Honoré (1992) for details.

Results can be found in Table 9, columns (5) and (6). As expected, first difference estimates of the return to occupation- and task tenure are smaller than the OLS and control function estimates. ${ }^{15}$ Task

\footnotetext{
${ }^{14}$ There is a compelling reason for why first difference estimates result in a downward bias in the return to occupationand task-specific human capital. Workers who choose to switch occupations, or choose to move to a distant occupation, do so for a reason and therefore have typically less to lose than a randomly selected worker. However, there is also a reason why first difference estimates may not provide a lower bound to the return to task tenure: Some workers may have moved to a distant occupation because of a high return to human capital. These workers earn low current wages, but expect a higher than usual wage growth in the future.

${ }^{15}$ Note that due to differences in the econometric model, the results for the low- and medium-skilled cannot be directly
} 
tenure continues to be a significant source of individual wage growth even in the fixed effects model.

In addition to firm matches, we have so far also abstracted from occupational mobility along a job ladder (see Gibbons et al., 2005; Jovanovic and Yarkow, 1997; Yamaguchi, 2007a). Within our framework, job ladders can be modeled by relaxing the restriction that the occupation-specific weights add up to one. We would expect occupations that have a higher analytic and manual weight to be higher up the job ladder, and workers should move along the ladder as they become more experienced. While we do not explicitly analyze hierarchical occupation mobility in this paper, our control function estimates is consistent even in the presence of career mobility. This is because the validity our instruments, in particular the deviation of occupation tenure from its occupation-specific mean, does not rely on the assumption that the occupation-specific weights add up to one.

In sum, the robustness of our results to alternative estimation techniques suggests that task-specific human capital is indeed an important source of individual wage growth.

\section{Conclusion}

How general is human capital? The evidence in this paper demonstrates that specific skills are more portable than previously considered. We show that workers are much more likely to move to occupations that require similar skills and that the distance of occupational moves declines over the life-cycle. Furthermore, wages and occupation tenure at the source occupation have a stronger impact on current wages if workers switch to a similar occupation.

The evidence also suggests that task-specific human capital is an important source of individual wage growth, in particular for university graduates. For them, at least 40 percent of wage growth due to human capital accumulation can be attributed to task-specific human capital, while occupation-specific skills and experience account for 14 and 47 percent respectively. For the medium-skilled (low-skilled), at least 25 (35) percent of individual wage growth is due to task-specific human capital. We also provide

compared to those of the high-skilled. Also note that in the first difference regression, the coefficient on (the change in) experience should not be interpreted as returns to general human capital accumulation, as they additionally reflect the change in the firm and task match quality. 
evidence that the costs of displacement and job reallocation depend on the employment opportunities after displacement: Wage losses are lower if individuals are able to find employment in an occupation with similar skill requirements.

Our findings on both mobility patterns and wage effects are strongest for the high-skilled, suggesting that task-specific skills are especially important for this education group. One explanation for this pattern could be that formal education and task-specific human capital are complements in production. Complementarity implies that high-skilled workers accumulate more task human capital on the job which would account for the sharp decline in the distance of moves over the life cycle. It would also explain why wages in the previous occupation are less valuable in the new occupation and why returns to task human capital are higher than for the two other education groups.

The results in this paper are difficult to reconcile with a standard human capital model with either fully general or firm- (or occupation-) specific skills. Our findings also contradict undirected search models of turnover where the current occupation has no effect on future occupational choices, and skills are not transferable across occupations. The findings however support a task-based approach to modeling labor market skills in which workers can transfer specific human capital across occupations.

\section{References}

[1] Abraham, K. G., and H. S. Farber (1987), "Job Duration, Seniority, and Earnings," American Economic Review, 77, 278-97.

[2] Adda, J., Dustmann, C., Meghir, C., and J.-M. Robin (2006), "Career Progression and Formal versus On-the-Job Training," IZA Discussion Paper No. 2260.

[3] Altonji, J. and R. Shakotko (1987), "Do Wages Rise with Job Seniority?," Review of Economic Studies, 54, 437-59.

[4] Altonji, J. and N. Williams (2005), "Do Wages Rise with Job Seniority? A Reassessment," Industrial and Labor Relations Review, 58, 370-97.

[5] Autor, D., R. Levy and R.J. Murnane (2003), "The Skill Content of Recent Technological Change: An Empirical Investigation", Quarterly Journal of Economics, 118, 1279-1333.

[6] Becker, G.S. (1964), Human Capital, University of Chicago Press.

[7] Ben-Porath, Y. (1967), "The Production of Human Capital and the Life-Cycle of Earnings," Journal of Political Economy, 75, 352-65. 
[8] Blundell, R. and J. Powell (2004), "Censored Regression Quantiles with Endogenous Regressors", mimeo, University of California at Berkeley.

[9] Borghans, L., B. ter Weel and B.A. Weinberg (2006), "Interpersonal Styles and Labor Market Outcomes, " mimeo, Maastricht University.

[10] DiNardo, J. and J.-S. Pischke (1997), "The Returns to Computer Use Revisited: Have Pencils Changed the Wage Structure Too?," Quarterly Journal of Economics, 112, 291-303.

[11] Dustmann, C. and C. Meghir (2005), "Wages, Experience and Seniority," Review of Economic Studies, 72, 77-108.

[12] Farber, H. (1999), "Mobility and Stability: The Dynamics of Job Change in Labor Markets," in: Handbook of Labor Economics, volume 3, edited by O. Ashenfelter and D Card, Elsevier Science.

[13] Fitzenberger, B. and A. Kunze (2005), "Vocational Training and Gender: Wages and Occupational Mobility among Young Workers," Oxford Review of Economic Policy, 21, 392-415.

[14] Fitzenberger, B. and A. Spitz-Öner (2004), "Die Anatomie des Berufswechsels: Eine empirische Bestandsaufnahme auf Basis der BiBB/IAB-Daten 1998/99," in: W. Franz, H.J. Ramser und M. Stadler, Bildung, Wirtschaftswissenschaftliches Seminar in Ottobeuren, Bd. 33, Tübingen, 29-54.

[15] Flinn, C. (1986), "Wages and Job Mobility of Young Workers," Journal of Political Economy, 84, S88-S110.

[16] Gibbons, R. and L.F. Katz (1991): "Layoffs and Lemons," Journal of Labor Economics, 9, 351-80.

[17] Gibbons, R.; L.F. Katz; T. Lemieux and D. Parent (2005): "Comparative Advantage, Learning and Sectoral Wage Determination," Journal of Labor Economics, 23, 681-724.

[18] Heckman, J.J. and G. Sedlacek (1985), "Heterogeneity, Aggregation, and Market Wage Functions: An Empirical Model of Self-Selection in the Labor Market," Journal of Political Economy, 93: 1077-1125.

[19] Heckman, J.J. and E. Vytlacil (1998), "Instrumental Variables Methods for the Correlated Random Coefficient Model," Journal of Human Resources, 1998, 33, 974-1002.

[20] Honoré, B. (1992), "Trimmed LAD and Least Squares Estimation of Truncated and Censored Regression Models with Fixed Effects," Econometrica, 60, 533-65.

[21] Ingram, B.F. and G. Neumann (2006), "The Return to Skill," Labour Economics, forthcoming.

[22] Jaffe, A.B. (1986), "Technological Opportunity and Spillover of R\&D: Evidence from Firms' Patents, Profits, and Market Value," American Economic Review, 76, 984-1001.

[23] Jovanovic, B. (1979a), "Firm Specific Capital and Turnover," Journal of Political Economy, 87, 1246-60.

[24] Jovanovic, B. (1979b), "Job Matching and the Theory of Turnover," Journal of Political Economy, 87, 972-90.

[25] Jovanovic, B. and Y. Yarkow (1997), "Stepping-Stone Mobility", Carnegie-Rochester Series of Public Policy, 46, 289-325. 
[26] Kambourov, G. and I. Manovskii (2004), "Occupational Mobility and Wage Inequality," mimeo, University of Toronto.

[27] Kambourov, G. and I. Manovskii (2007), "Occupational Specificity of Human Capital," International Economic Review, forthcoming.

[28] Kletzer, L. (1989), "Returns to Seniority after Permanent Job Loss," American Economic Review, $79,536-53$.

[29] Lazear, E.P. (2003), "Firm-Specific Human Capital: A Skill-Weights Approach," NBER Working Paper W9679.

[30] Ljungqvist, L. and T.J. Sargent (1998), "The European Unemployment Dilemma," Journal of Political Economy, 106, 514-550.

[31] Malamud, O. (2005), "Breadth vs. Depth : The Effect of Academic Specialization on Labor Market Outcomes," Harris School Working Paper Series 05.17.

[32] McCall, B.P. (1990), "Occupational Matching: A Test of Sorts," Journal of Political Economy, 98: 45-69.

[33] Miller, R. (1984), "Job Matching and Occupational Choice," Journal of Political Economy, 92: 1086-1120

[34] Mincer, J. (1974), Schooling, Experience and Earnings, Columbia University Press.

[35] Murphy, K.M. (1986), "Specialization and Human Capital," Unpublished Dissertation, University of Chicago.

[36] Neal, D. (1995), "Industry-Specific Capital: Evidence from Displaced Workers," Journal of Labor Economics, 13: 653-77.

[37] Neal, D. (1999), "The Complexity of Job Mobility among Young Men," Journal of Labor Economics, 17: $237-61$.

[38] Parent, D. (2000), "Industry-Specific Capital and the Wage Profile: Evidence from the National Longitudinal Study of Income Dynamics," Journal of Labor Economics, 18: 306-23.

[39] Pavan, R. (2005), "Career Choice and Wage Growth," mimeo, University of Chicago.

[40] Poletaev, M. and C. Robinson (2004) , "Human Capital and Skill Specificity," CBIC working paper, University of Western Ontario.

[41] Rosen, S. (1983), "Specialization and Human Capital," Journal of Labor Economics, 1, 43-49.

[42] Roy, A.D. "Some Thoughts on the Distribution of Earnings," Oxford Economic Papers, 3, 135-146.

[43] Shaw, K. (1984), "A Formulation of the Earnings Function Using the Concept of Occupational Investment," Journal of Human Resources, 19. 319-340.

[44] Shaw, K. (1987), "Occupational Change, Employer Change, and the Transferability of Skills," Southern Economic Journal, 53: 702-19.

[45] Spitz-Öner, A. (2006), "Technical Change, Job Tasks, and Rising Educational Demands: Looking Outside the Wage Structure," Journal of Labor Economics, 24, 235-70. 
[46] Topel, R. (1991), "Specific Capital, Mobility and Wages: Wages Rise with Job Seniority," Journal of Political Economy, 99, 145-76.

[47] Topel, R. and M. Ward (1992), "Job Mobility and the Careers of Young Men," Quarterly Journal of Economics, 107, 439-80.

[48] Violante, G.L. (2002), "Technological Acceleration, Skill Transferability, and the Rise in Residual Inequality," Quarterly Journal of Economics, 117, 297-338.

[49] Wasmer, E. (2004), "Interpreting Europe and US Labor Markets Differences: The Specificity of Human Capital Investments," American Economic Review, 96, 811-831.

[50] Yamaguchi, S. (2007a), "Career and Skill Formation: A Dynamic Occupational Choice Model with Multidimensional Skills," mimeo, McMaster University.

[51] Yamaguchi, S. (2007b), "The Effect of Match Quality and Specific Experience on Career Decisions and Wage Growth," mimeo, McMaster University.

\section{A Data Sources}

\section{A.1 Data on Occupational Tasks (1979-1999)}

We use four cross-sections of the German Qualification and Career Survey conducted in 1979, 1985, 1991/92 and 1998/99 by the Federal Institute of Vocational Training (BIBB) and the Institute for Labor Market Research (IAB). The data with a sample size of 30,000 covers individuals between 16 and 65, who are employed at the time of the survey. We restrict our sample to men employed in West Germany and exclude the self-employed, civil servants and those working in agriculture. We also exclude those without German nationality since they were not included in each wave. We use the same 64 occupations based on a classification system by the Federal Employment Office, which is standardized over time. The aggregation at the 2-digit level decreases well-known measurement error problems of occupational classifications in survey data and allows us to match the data to our main data set on job histories.

For each respondent, we know whether the worker performs certain tasks in his job and whether this is his main activity on the job. Unlike the Dictionary of Occupational Titles (DOT) in the United States, we do not know how intensively a particular task is used beyond the distinction of main activity, task performed and not performed. Overall, we have information on 19 different tasks workers perform in their jobs. Following Autor et al. (2003), we group the 19 tasks into three groups of tasks: analytical tasks, manual tasks and interactive tasks. The assignment of tasks is as follows: manual tasks (equip or operate machines, repair, reconstruct or renovate, cultivate, manufacture, cleaning, serve or accommodate, construct or install, pack or ship or transport, secure, nurse or treat others), analytical tasks (research or evaluate or measure, design or plan or sketch, correct texts or data, bookkeeping or calculate, program, execute laws or interpret rules) and interactive tasks (sell or buy or advertise, teach or train others, publish or present or entertain, employ or manage personnel or organize or coordinate). 


\section{A.2 Employee Sample (1975-2001)}

Our main data set is a two percent sample of all German social security records administered by the Institute for Employment Research. By law, employers are required to report the exact beginning and end of any employment relation of new hires and employees leaving the firm which are subject to social security contributions. In addition, employers provide information about all their employees at the end of each year. We therefore know the exact date of employer changes and movements into and out of paid employment. Another advantage is that the data contain an unusually in-depth set of background information for each individual, including his age, education, gender, nationality, plant of work and occupation. We distinguish three education levels: low-, medium-, and high-skilled. We define a worker to be high-skilled if at least one spell classifies him as a graduate from a university or technical college. (Fachhochschule). A worker is medium-skilled if he spent at least 450 days in apprenticeship training, and no spell classifies him as a college graduate. A worker is low-skilled if he spent less than 450 days in apprenticeship training and did not attend a technical college or university. The occupational categories of employees and apprentices in the social security records are highly accurate as the classification forms the basis of wage agreements between unions and employers' association. To make the 130 different occupations we observe in our sample comparable to the BIBB data, we aggregated them into 64 occupations at the 2-digit level using a code provided to us by the Institute for Employment Research. All experience and tenure variables refer to the beginning of each spell. Time out of the labor force and time in unemployment as well time in apprenticeship training is not counted. If an employee returns to his occupation, we count the time spent in the earlier spell towards his occupational tenure. The same holds in the unlikely event that a worker returns to a firm he has worked for previously. Our results on occupational movers exclude these return movers, but the estimates are similar if they are included.

In addition to the sample restrictions mentioned in the text, we dropped all spells in vocational training and those job spells that started prior to an apprenticeship or tertiary education. In addition, we excluded observations that were still in vocational training at the end of the sample period in 2001 or pursued more than one apprenticeship, that is were employed as an apprentice for more than 7 years. We also require a person to be below a certain age when we first observe them. This ensures that we can follow them from day one of their entry into the labor market. The age restriction is 19 if the individual has no high school degree (Abitur), 22 if the individual has a high school degree, but no higher degree, 28 if the individual graduated from a community college (Fachhochschule), and 30 if he graduated from university. Finally, we drop all observations we observe less than a year, with missing education or nationality, and observations with no valid wage or a daily (real) wage below 20 DM during an employment spell. To estimate the returns to different types of human capital in Section 5, we use a sample of displaced workers. A worker is displaced from his firm due to plant closure if he left the firm in the year or one year before the firm closed down. As a robustness check, we have repeated the analysis restricting the sample to workers who have left the firm in the year or one or two year before the firm closed down. The first definition has the advantage that it includes less workers who have left the firm voluntarily, for reasons other than plant closure. It has the disadvantage that it may exclude workers that leave the firm prior to plant closure, anticipating that the firm may shut down in the future. Both definitions give very similar results. 


\section{B Blundell and Powell (2004) Control Variable Estimator}

For the high-skilled, the control variable estimates in Table 9, columns (1) to (4) are based on the semiparametric estimator proposed by Blundell and Powell (2004). This estimator accounts for censoring in addition to endogenous regressors. It does so however at the price of imposing common returns on the observable human capital variables. For simplicity, we drop the subscript $o$. The model is

$$
\ln W_{i t}=\min \left\{X_{i t} \beta+u_{i t}, c_{t}\right\}
$$

where $X_{i t}$ are the endogenous regressors, $u_{i t}$ is the scalar error term and $c_{t}$ is the time-dependent censoring point. For notational convenience, we suppress all exogenous regressors here. The reduced form links the instruments $Z_{i t}$ to the endogenous regressors:

$$
X_{i t}=Z_{i t} \gamma+v_{i t}
$$

where $v_{i t}$ is a scalar error term and $\gamma$ the unknown coefficient vector with suitable dimensions. Instead of imposing independence between $\left(u_{i t}, v_{i t}\right)$ and $Z_{i t}$, the estimator imposes a weaker conditional quantile exclusion restriction

$$
F_{u}\left(q \mid X_{i t}, Z_{i t}\right) \equiv \operatorname{Pr}\left\{u_{i t} \leq q \mid X_{i t}, Z_{i t}\right\}=\operatorname{Pr}\left\{u_{i t} \leq q \mid v_{i t}\right\}=F_{u}\left(q \mid v_{i t}\right) \quad q \in R
$$

This assumption implies that the dependence of the regressors $X_{i o t}$ and the error term $u_{i t}$ is driven by the residuals $v_{i t}$ (control variable). To consistently estimate the reduced-form above, we also require that $E\left[v_{i t} \mid Z_{i t}\right]=0$. The estimation then proceeds as follows: first, we predict $\widehat{v_{i t}}$ from regressions of the endogenous regressors on the instruments and the other control variables. Then, we estimate a quantile regression of the dependent variables on both the endogenous regressors and the instruments as well as the control variables to obtain the fitted values $\widehat{\ln W_{i t}}$. The second step is to estimate a weighted least squares regression of all pairwise differences of the predicted dependent variable $\widehat{\ln W_{i t}}$ on the endogenous regressors $X_{i t}$. The weights are the pairwise differences of the residuals $\widehat{v_{i t}}$, which are used as inputs into a multivariate kernel function. Formally, the second-stage estimator is defined as

$$
\begin{aligned}
\widehat{\beta}= & {\left[\sum_{s<t} \sum_{i<j} K_{v}\left(\frac{\widehat{v_{i s}}-\widehat{v_{j t}}}{h_{n}}\right) \widehat{t_{i s}} \widehat{t_{j t}}\left(X_{i s}-X_{j t}\right)^{\prime}\left(X_{i s}-X_{j t}\right)\right]^{-1} \times } \\
& {\left[\sum_{s<t} \sum_{i<j} K_{v}\left(\frac{\widehat{v_{i s}}-\widehat{v_{j t}}}{h_{n}}\right) \widehat{t_{i s}} \widehat{t_{j t}}\left(X_{i s}-X_{j t}\right)^{\prime}\left(\widehat{\ln W}_{i s}-\widehat{\ln W}_{j t}\right)\right] }
\end{aligned}
$$

where $K_{v}(\cdot)$ is the kernel function and $h_{n}$ is a sequence of scalar bandwidth terms. $\widehat{t_{i s}}$ is a "trimming" term, constructed so that $\widehat{t i s_{i s}}=0$ unless the estimated quantiles $\widehat{\ln W}_{i s}>0$ and $X_{i s}$ and $v_{i s}$ fall in some compact set $S$. We used the product epanechnikov kernel and a separate bandwidth $h_{n}$ for each endogenous variable. Standard errors were again bootstrapped using 100 replications. 
Table 1: Summary Statistics of Task Data

\begin{tabular}{|c|c|c|c|c|}
\hline & Mean & Std.Dev & Example: Teacher & Example: Baker \\
\hline Analytical Tasks & 55.02 & 49.75 & $63.73 \%$ & $32.42 \%$ \\
\hline Research, evaluate or measure & 25.11 & 43.37 & $34.02 \%$ & $13.56 \%$ \\
\hline Design, plan or sketch & 10.21 & 30.28 & $17.62 \%$ & $3.60 \%$ \\
\hline Correct texts or data & 23.85 & 42.62 & $39.64 \%$ & $6.36 \%$ \\
\hline Calculate or bookkeeping & 26.02 & 43.87 & $11.34 \%$ & $22.46 \%$ \\
\hline Program & 8.35 & 27.66 & $8.43 \%$ & $0.42 \%$ \\
\hline Execute laws or interpret rules & 7.85 & 26.89 & $17.24 \%$ & $0.85 \%$ \\
\hline Analytical is Main Task & 31.56 & 46.48 & $15.93 \%$ & $13.14 \%$ \\
\hline Manual Tasks & 72.42 & 44.69 & $25.59 \%$ & $96.40 \%$ \\
\hline Equip or operate machines & 19.98 & 39.99 & $7.03 \%$ & $27.12 \%$ \\
\hline Repair, renovate or reconstruct & 31.38 & 46.40 & $8.15 \%$ & $10.38 \%$ \\
\hline Cultivate & 1.77 & 13.19 & $2.25 \%$ & $1.91 \%$ \\
\hline Manufacture, install or construct & 11.97 & 32.46 & $1.97 \%$ & $87.92 \%$ \\
\hline Cleaning & 3.50 & 18.38 & $1.78 \%$ & $6.14 \%$ \\
\hline Serve or accommodate & 1.21 & 10.92 & $0.28 \%$ & $3.60 \%$ \\
\hline Pack, ship or transport & 18.76 & 39.04 & $2.72 \%$ & $15.25 \%$ \\
\hline Secure & 15.72 & 36.40 & $7.22 \%$ & $18.01 \%$ \\
\hline Nurse or treat others & 9.76 & 29.67 & $11.53 \%$ & $7.84 \%$ \\
\hline Manual is Main Task & 57.46 & 49.44 & $10.50 \%$ & $88.77 \%$ \\
\hline Interactive Tasks & 48.48 & 49.98 & $95.31 \%$ & $44.07 \%$ \\
\hline Sell, buy or advertise & 29.21 & 45.48 & $12.00 \%$ & $16.53 \%$ \\
\hline Teach or train others & 17.15 & 37.69 & $91.38 \%$ & $34.32 \%$ \\
\hline Publish, present or entertain others & 9.58 & 29.43 & $26.24 \%$ & $3.81 \%$ \\
\hline Employ, manage personnel, organize, coord & 37.09 & 48.31 & $39.36 \%$ & $29.87 \%$ \\
\hline Interactive is Main Task & 27.55 & 44.68 & $85.94 \%$ & $14.83 \%$ \\
\hline Observations & 52,718 & & 1,067 & 472 \\
\hline
\end{tabular}

Notes: The table reports the percentage of individuals in the career survey that report performing the type of task in their job. We grouped the 19 different tasks into three task groups (analytical, manual and interactive skills) following Autor et al. (2003) and Spitz (2006). The fraction for main tasks sum to more than 100 percent as around 10 percent reported performing more than one main task. The last two columns show the distribution of task usage for two common occupations: teachers (which exclude university or technical college professors) and baker. 
Table 2: Measuring Distances between Occupations

\begin{tabular}{|c|c|c|}
\hline \multicolumn{3}{|c|}{ Distance Measure (Angular separation) } \\
\hline Occupation 1 & Occupation 2 & Distance \\
\hline \multicolumn{2}{|l|}{ Mean } & 0.244 \\
\hline \multicolumn{2}{|l|}{ Standard Deviation } & 0.221 \\
\hline \multicolumn{3}{|c|}{ Most Similar (all Education Groups) } \\
\hline Paper and Pulp Processing & Printer, Typesetter & 0.002 \\
\hline Wood Processing & Metal Polisher & 0.003 \\
\hline Chemical Processing & Plastics Processing & 0.004 \\
\hline \multicolumn{3}{|c|}{ Most Distant (all Education Groups) } \\
\hline Banker & Unskilled Construction Worker & 0.939 \\
\hline Banker & Miner, Stone-Breakers & 0.935 \\
\hline Publicists, Journalist & Unskilled Construction Worker & 0.933 \\
\hline \multicolumn{3}{|c|}{ Most Common Occupational Moves (Low-Skilled) } \\
\hline Truck Driver, Conductor & Store or Warehouse Keeper & 0.029 \\
\hline Unskilled Worker & Store or Warehouse Keeper & 0.267 \\
\hline Assembler & Store or Warehouse Keeper & 0.372 \\
\hline \multicolumn{3}{|c|}{ Most Common Occupational Moves (Medium-Skilled) } \\
\hline Chemist, Physicist & Electricians, Electrical Installation & 0.171 \\
\hline Sales Personnel & Office Clerk & 0.077 \\
\hline Truck Driver, Conductor & Store or Warehouse Keeper & 0.028 \\
\hline \multicolumn{3}{|c|}{ Most Common Occupational Moves (High-Skilled) } \\
\hline Engineers & Chemist, Physicist & 0.037 \\
\hline Entrepreneurs & Office Clerk & 0.048 \\
\hline Accountant & Office Clerk & 0.080 \\
\hline
\end{tabular}

Notes: The table shows at the top summary statistics of the distance measure as well as the three most similar and distant occupations and their corresponding distance. The distance measure is the angular separation using the 19 different tasks (see Table B1 for a list of tasks) and normalized to vary between 0 and 1 . The bottom part of the table shows the three most commonly observed moves in the data by education group and the corresponding distance measure. 
Table 3: Summary Statistics of West German Employee Panel

\begin{tabular}{|c|c|c|c|}
\hline & Low Skill & Medium Skill & High Skill \\
\hline Percentage in Sample & $16.27 \%$ & $68.30 \%$ & $15.43 \%$ \\
\hline \multirow[t]{2}{*}{ Age (in Years) } & 25.82 & 27.47 & 31.85 \\
\hline & $(6.26)$ & $(5.24)$ & $(5.60)$ \\
\hline \multirow[t]{2}{*}{ Not German Citizen } & 0.32 & 0.052 & 0.047 \\
\hline & $(0.47)$ & $(0.22)$ & $(0.21)$ \\
\hline \multirow[t]{2}{*}{ Median Daily Wage } & 114.39 & 135.32 & 204.23 \\
\hline & $(45.44)$ & $(43.52)$ & $(61.43)$ \\
\hline \multirow[t]{2}{*}{ Log Daily Wage } & 4.66 & 4.89 & 5.19 \\
\hline & $(0.45)$ & $(0.33)$ & $(0.43)$ \\
\hline \multirow[t]{2}{*}{ Percentage censored } & 0.01 & 0.02 & 0.24 \\
\hline & $(0.10)$ & $(0.14)$ & $(0.43)$ \\
\hline \multirow[t]{2}{*}{ Actual Experience (in Years) } & 5.76 & 5.59 & 5.25 \\
\hline & $(5.40)$ & $(4.76)$ & $(4.81)$ \\
\hline \multirow[t]{2}{*}{ Occupational Tenure (in Years) } & 3.28 & 3.87 & 3.62 \\
\hline & $(4.27)$ & $(4.12)$ & $(4.07)$ \\
\hline \multirow[t]{2}{*}{ Firm Tenure (in Years) } & 2.47 & 2.79 & 2.46 \\
\hline & $(3.87)$ & $(3.66)$ & (3.33) \\
\hline \multirow[t]{2}{*}{ Task Tenure (in Years) } & 4.58 & 4.81 & 4.66 \\
\hline & $(4.65)$ & $(4.28)$ & $(4.38)$ \\
\hline \multirow[t]{2}{*}{ Occupational Mobility } & 0.186 & 0.114 & 0.109 \\
\hline & $(0.389)$ & $(0.317)$ & $(0.311)$ \\
\hline \multirow[t]{2}{*}{ Distance of Move } & 0.054 & 0.0525 & 0.0441 \\
\hline & $(0.025)$ & $(0.025)$ & $(0.024)$ \\
\hline \multirow[t]{2}{*}{ Firm Mobility } & 0.236 & 0.18 & 0.18 \\
\hline & $(0.425)$ & $(0.384)$ & $(0.384)$ \\
\hline \multirow[t]{5}{*}{ Most Common Occupations } & Warehouse Keeper (10\%) & Electrical Installation (7\%) & Engineer (25\%) \\
\hline & Assembler $(7 \%)$ & Locksmith (8\%) & Technician (12\%) \\
\hline & Conductor (6\%) & Mechanic, Machinist (6\%) & Accountant (9\%) \\
\hline & Unskilled Worker (4\%) & Office Clerk (7\%) & Office Clerk (8\%) \\
\hline & Office Clerk (4\%) & Conductor $(5 \%)$ & Researcher, Clergymen (5\%) \\
\hline Number of Observations & 223,399 & $1,000,934$ & 197,420 \\
\hline Number of Individuals & 18,604 & 78,101 & 17,648 \\
\hline
\end{tabular}

Source: Employee Sample (IAB), 1975-2001 


\section{Table 4: Observed Moves are More Similar than under Random Mobility}

\begin{tabular}{lcc}
\hline & Random Mobility & Observed Mobility \\
\hline \hline Mean & 0.466 & 0.409 \\
10th Percentile & 0.083 & 0.047 \\
25th Percentile & 0.267 & 0.122 \\
50th Percentile & 0.507 & 0.381 \\
75th Percentile & 0.668 & 0.595 \\
90th Percentile & 0.776 & 0.682
\end{tabular}

Notes: The table repports selected moments of the distribution of observed occupational moves ("Observed Mobility") and compares it against what we would expect to observe under random mobility ("Random Mobility"). We calculate random mobility as follows: for each mover, we assume that the probability of going to any other occupation in the data is solely determined by the relative size of the target occupation. We then multiply this "random move" with its distance to get the distribution of the distance measure under random mobility. The distance measure is the angular separation, based on 19 tasks. Since all moments of the observed distribution are below those under random mobility, individuals are much more likely to move to similar occupation. 
Table 5: Distance of Move Declines with Time in the Labor Market

\begin{tabular}{|c|c|c|c|c|c|c|c|c|c|}
\hline \multirow[b]{2}{*}{ Y: Distance of Move } & \multicolumn{3}{|c|}{ Low-Skilled } & \multicolumn{3}{|c|}{ Medium-Skilled } & \multicolumn{3}{|c|}{ High-Skilled } \\
\hline & $(1)$ & $(2)$ & (3) & $(1)$ & $(2)$ & (3) & $(1)$ & $(2)$ & $(3)$ \\
\hline Experience & $\begin{array}{c}-0.005 \\
(0.001)^{\star *}\end{array}$ & $\begin{array}{c}-0.005 \\
(0.001)^{\star *}\end{array}$ & $\begin{array}{c}-0.004 \\
(0.002)^{\star \star}\end{array}$ & $\begin{array}{c}-0.003 \\
(0.000)^{\star *}\end{array}$ & $\begin{array}{c}-0.003 \\
(0.000)^{\star *}\end{array}$ & $\begin{array}{c}-0.003 \\
(0.001)^{\star \star}\end{array}$ & $\begin{array}{c}-0.016 \\
(0.001)^{\star *}\end{array}$ & $\begin{array}{c}-0.015 \\
(0.001)^{\star *}\end{array}$ & $\begin{array}{c}-0.017 \\
(0.003)^{\star \star}\end{array}$ \\
\hline Experience Squared & $\begin{array}{c}0.000 \\
(0.000)^{\star \star}\end{array}$ & $\begin{array}{c}0.000 \\
(0.000)^{\star \star}\end{array}$ & $\begin{array}{c}0.000 \\
(0.000)^{\star \star}\end{array}$ & $\begin{array}{c}0.000 \\
(0.000)^{\star \star}\end{array}$ & $\begin{array}{c}0.000 \\
(0.000)^{\star \star}\end{array}$ & $\begin{array}{c}0.000 \\
(0.000)^{\star \star}\end{array}$ & $\begin{array}{c}0.001 \\
(0.000)^{\star \star}\end{array}$ & $\begin{array}{c}0.001 \\
(0.000)^{\star \star}\end{array}$ & $\begin{array}{c}0.001 \\
(0.000)^{\star \star}\end{array}$ \\
\hline Occupation Tenure & & $\begin{array}{c}-0.003 \\
(0.001)^{\star \star}\end{array}$ & $\begin{array}{c}-0.002 \\
(0.001)^{\star}\end{array}$ & & $\begin{array}{l}0.000 \\
0.000\end{array}$ & $\begin{array}{c}0.002 \\
(0.000)^{\star \star}\end{array}$ & & $\begin{array}{c}-0.003 \\
(0.001)^{\star \star}\end{array}$ & $\begin{array}{r}0.000 \\
-0.001\end{array}$ \\
\hline Constant & $\begin{array}{c}0.382 \\
(0.012)^{\star \star}\end{array}$ & $\begin{array}{c}0.385 \\
(0.012)^{\star \star}\end{array}$ & $\begin{array}{c}0.377 \\
(0.018)^{\star \star}\end{array}$ & $\begin{array}{c}0.391 \\
(0.015)^{\star \star}\end{array}$ & $\begin{array}{c}0.391 \\
(0.015)^{\star \star}\end{array}$ & $\begin{array}{c}0.346 \\
(0.022)^{\star \star}\end{array}$ & $\begin{array}{c}0.397 \\
(0.046)^{\star \star}\end{array}$ & $\begin{array}{c}0.399 \\
(0.045)^{\star \star}\end{array}$ & $\begin{array}{c}0.258 \\
(0.062)^{\star \star}\end{array}$ \\
\hline Year Dummies & Yes & Yes & Yes & Yes & Yes & Yes & Yes & Yes & Yes \\
\hline Occupation Dummies & Yes & Yes & Yes & Yes & Yes & Yes & Yes & Yes & Yes \\
\hline Individual Fixed Effects & No & No & Yes & No & No & Yes & No & No & Yes \\
\hline Observations & 44,149 & 44,149 & 44,149 & 117,206 & 117,206 & 117,206 & 20,947 & 20,947 & 20,947 \\
\hline Mean Distance of Move & $\begin{array}{c}0.2757 \\
(0.2255)\end{array}$ & $\begin{array}{c}0.276 \\
(0.226)\end{array}$ & $\begin{array}{c}0.276 \\
(0.226)\end{array}$ & $\begin{array}{c}0.243 \\
(0.220)\end{array}$ & $\begin{array}{c}0.243 \\
(0.220)\end{array}$ & $\begin{array}{c}0.243 \\
(0.220)\end{array}$ & $\begin{array}{c}0.185 \\
(0.202)\end{array}$ & $\begin{array}{c}0.185 \\
(0.202)\end{array}$ & $\begin{array}{c}0.185 \\
(0.202)\end{array}$ \\
\hline
\end{tabular}

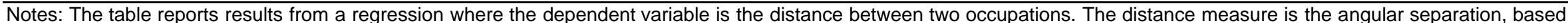

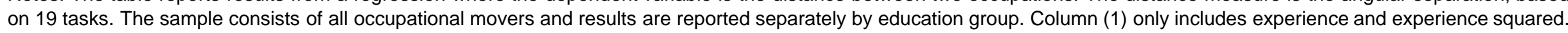

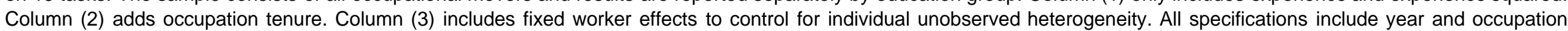

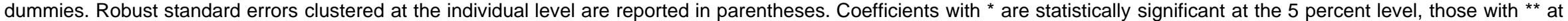
the 1 percent level. 
Table 6: Similar Moves and the Correlation of Wages Across Jobs

\begin{tabular}{|c|c|c|c|c|c|c|c|c|c|}
\hline \multirow[b]{2}{*}{ Y: Log Daily Wage after Move } & \multicolumn{3}{|c|}{ Low-Skilled } & \multicolumn{3}{|c|}{ Medium-Skilled } & \multicolumn{3}{|c|}{ High-Skilled } \\
\hline & $(1)$ & $(2)$ & $(3)$ & $(1)$ & $(2)$ & $(3)$ & $(1)$ & $(2)$ & $(3)$ \\
\hline Wage Last Period & $\begin{array}{c}0.783 \\
(0.004)^{\star \star}\end{array}$ & $\begin{array}{c}0.220 \\
(0.007)^{\star \star}\end{array}$ & $\begin{array}{c}0.252 \\
(0.010)^{\star \star}\end{array}$ & $\begin{array}{c}0.787 \\
(0.002)^{\star \star}\end{array}$ & $\begin{array}{c}0.328 \\
(0.004)^{\star \star}\end{array}$ & $\begin{array}{c}0.381 \\
(0.006)^{\star \star}\end{array}$ & $\begin{array}{c}0.890 \\
(0.005)^{\star \star}\end{array}$ & $\begin{array}{c}0.296 \\
(0.010)^{\star \star}\end{array}$ & $\begin{array}{c}0.351 \\
(0.011)^{\star \star}\end{array}$ \\
\hline Wage Last Period*Distance & & & $\begin{array}{c}-0.127 \\
(0.023)^{\star \star}\end{array}$ & & & $\begin{array}{c}-0.243 \\
(0.015)^{\star \star}\end{array}$ & & & $\begin{array}{c}-0.354 \\
(0.032)^{\star \star}\end{array}$ \\
\hline Distance of Move & & & $\begin{array}{c}0.495 \\
(0.101)^{\star \star}\end{array}$ & & & $\begin{array}{c}1.040 \\
(0.069)^{\star \star}\end{array}$ & & & $\begin{array}{c}1.481 \\
(0.152)^{\star \star}\end{array}$ \\
\hline Year Dummies & Yes & Yes & Yes & Yes & Yes & Yes & Yes & Yes & Yes \\
\hline Occupation Dummies & Yes & Yes & Yes & Yes & Yes & Yes & Yes & Yes & Yes \\
\hline Observations & 158,808 & 44,137 & 44,137 & 802,197 & 117,204 & 117,204 & 158,416 & 18,285 & 18,285 \\
\hline
\end{tabular}

Notes: The table reports results from wage regressions where the dependent variable is the log daily wages at the target occupation after an occupational move. Results are reported separately by education group. For the low-

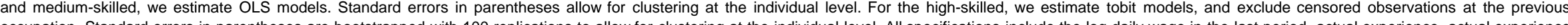

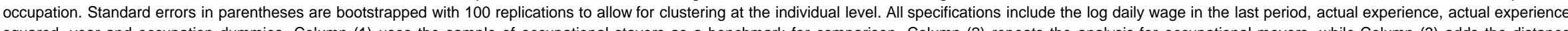

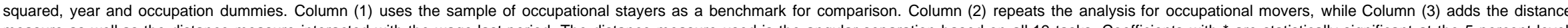

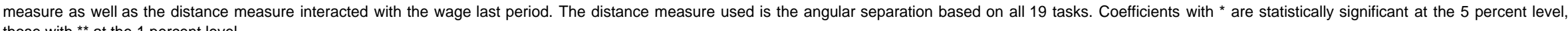
those with ** at the 1 percent level. 
Table 7: Past Occupational Tenure Matters for Wages

\begin{tabular}{|c|c|c|c|c|c|c|}
\hline \multirow[b]{2}{*}{ Y: Log Daily Wage after Move } & \multicolumn{2}{|c|}{ Low-Skilled } & \multicolumn{2}{|c|}{ Medium-Skilled } & \multicolumn{2}{|c|}{ High-Skilled } \\
\hline & $(1)$ & $(2)$ & $(1)$ & $(2)$ & $(1)$ & $(2)$ \\
\hline Past Occupational Tenure & $\begin{array}{c}0.015 \\
(0.001)^{\star \star}\end{array}$ & $\begin{array}{c}0.018 \\
(0.001)^{\star \star}\end{array}$ & $\begin{array}{c}0.013 \\
(0.0005)^{\star \star}\end{array}$ & $\begin{array}{c}0.016 \\
(0.0006)^{\star \star}\end{array}$ & $\begin{array}{c}0.015 \\
(0.002)^{\star \star}\end{array}$ & $\begin{array}{c}0.023 \\
(0.002)^{\star \star}\end{array}$ \\
\hline Past Tenure *Distance & & $\begin{array}{c}-0.018 \\
(0.003)^{\star \star}\end{array}$ & & $\begin{array}{c}-0.022 \\
(0.002)^{\star \star}\end{array}$ & & $\begin{array}{c}-0.072 \\
(0.006)^{\star \star}\end{array}$ \\
\hline Year Dummies & Yes & Yes & Yes & Yes & Yes & Yes \\
\hline Occupational Dummies & Yes & Yes & Yes & Yes & Yes & Yes \\
\hline Observations & 44,149 & 44,149 & 117,206 & 117,206 & 20,947 & 20,947 \\
\hline
\end{tabular}

Notes: The table reports wage regressions where the dependent variable is the log wages in the target occupation after an occupational move. Estimates are reported for each education group separately. For the low- and medium-skilled, we report results from OLS regressions. Standard errors in parentheses allow for clustering at the individual level. For the high-skilled, we estimate tobit models. Here, standard errors in parentheses are bootstrapped with 100 replications to account for clustering at the individual level. Column (1) in each specification controls for past tenure in the source occupation, experience, experience squared, as well as year and occupation dummies. Column (2) additionally includes the distance measure interacted with past occupational tenure. The distance measure used is the angular separation based on all 19 tasks. Coefficients with * are statistically significant at the 5 percent level, those with ** at the 1 percent level. 
Table 8: Returns to Labor Market Skills: Least Squares

\begin{tabular}{|c|c|c|c|c|c|c|}
\hline \multirow{4}{*}{$\begin{array}{l}\text { Panel A: Low-Skilled } \\
\text { Task Tenure }\end{array}$} & \multicolumn{2}{|c|}{ Whole Sample } & \multicolumn{2}{|c|}{ Firm Switchers } & \multicolumn{2}{|c|}{ Displaced Workers } \\
\hline & \multirow[t]{2}{*}{$(1)$} & \multirow[t]{2}{*}{$(2)$} & \multirow[t]{2}{*}{ (3) } & \multirow[t]{2}{*}{$(4)$} & \multirow[t]{2}{*}{ (5) } & \multirow[t]{2}{*}{$(6)$} \\
\hline & & & & & & \\
\hline & & $\begin{array}{c}0.012 \\
(0.001)^{\star \star \star}\end{array}$ & & $\begin{array}{c}0.024 \\
(0.001)^{\star \star \star}\end{array}$ & & $\begin{array}{c}0.020 \\
(0.003)^{\star \star \star}\end{array}$ \\
\hline Occupational Tenure & $\begin{array}{c}0.009 \\
(0.001)^{\star \star \star}\end{array}$ & $\begin{array}{c}0.007 \\
(0.001)^{\star \star \star}\end{array}$ & $\begin{array}{c}0.021 \\
(0.001)^{\star \star \star}\end{array}$ & $\begin{array}{c}0.020 \\
(0.001)^{\star \star \star}\end{array}$ & $\begin{array}{c}0.016 \\
(0.002)^{\star \star \star}\end{array}$ & $\begin{array}{c}0.014 \\
(0.002)^{\star \star \star}\end{array}$ \\
\hline Experience & $\begin{array}{c}0.062 \\
(0.001)^{\star \star \star}\end{array}$ & $\begin{array}{c}0.054 \\
(0.001)^{\star \star \star}\end{array}$ & $\begin{array}{c}0.047 \\
(0.001)^{\star \star \star}\end{array}$ & $\begin{array}{c}0.032 \\
(0.002)^{\star \star \star}\end{array}$ & $\begin{array}{c}0.044 \\
(0.004)^{\star \star \star}\end{array}$ & $\begin{array}{c}0.031 \\
(0.004)^{\star \star \star}\end{array}$ \\
\hline Experience Squared & $\begin{array}{c}-0.002 \\
(0.000)^{\star \star \star}\end{array}$ & $\begin{array}{c}-0.002 \\
(0.000)^{\star \star \star}\end{array}$ & $\begin{array}{c}-0.002 \\
(0.000)^{\star \star \star}\end{array}$ & $\begin{array}{c}-0.002 \\
(0.000)^{\star \star \star}\end{array}$ & $\begin{array}{c}-0.001 \\
(0.000)^{\star \star \star}\end{array}$ & $\begin{array}{c}-0.001 \\
(0.000)^{\star \star \star}\end{array}$ \\
\hline Firm Tenure & $\begin{array}{c}0.008 \\
(0.001)^{\star \star \star}\end{array}$ & $\begin{array}{c}0.007 \\
(0.001)^{\star \star \star}\end{array}$ & & & & \\
\hline Observations & 202,327 & 202,327 & 56,831 & 56,831 & 5,891 & 5,891 \\
\hline R Squared & 0.370 & 0.370 & 0.250 & 0.250 & 0.300 & 0.310 \\
\hline \multicolumn{7}{|c|}{ Panel B: Medium-Skilled } \\
\hline Task Tenure & & $\begin{array}{c}0.009 \\
(0.0005)^{\star \star \star}\end{array}$ & & $\begin{array}{c}0.018 \\
(0.001)^{\star \star \star}\end{array}$ & & $\begin{array}{c}0.012 \\
(0.002)^{\star \star \star}\end{array}$ \\
\hline Occupational Tenure & $\begin{array}{c}0.007 \\
(0.000)^{\star \star \star}\end{array}$ & $\begin{array}{c}0.005 \\
(0.0003)^{\star \star \star}\end{array}$ & $\begin{array}{c}0.016 \\
(0.000)^{\star \star \star}\end{array}$ & $\begin{array}{c}0.014 \\
(0.000)^{\star \star \star}\end{array}$ & $\begin{array}{c}0.015 \\
(0.001)^{\star \star \star}\end{array}$ & $\begin{array}{c}0.013 \\
(0.001)^{\star \star \star}\end{array}$ \\
\hline Experience & $\begin{array}{c}0.040 \\
(0.000)^{\star \star \star}\end{array}$ & $\begin{array}{c}0.034 \\
(0.0006)^{\star \star \star}\end{array}$ & $\begin{array}{c}0.038 \\
(0.001)^{\star \star \star}\end{array}$ & $\begin{array}{c}0.026 \\
(0.001)^{\star \star \star}\end{array}$ & $\begin{array}{c}0.036 \\
(0.002)^{\star \star \star}\end{array}$ & $\begin{array}{c}0.028 \\
(0.002)^{\star \star \star}\end{array}$ \\
\hline Experience Squared & $\begin{array}{c}-0.001 \\
(0.000)^{\star \star \star}\end{array}$ & $\begin{array}{c}-0.001 \\
(0.0000)^{\star \star \star}\end{array}$ & $\begin{array}{c}-0.001 \\
(0.000)^{\star \star \star}\end{array}$ & $\begin{array}{c}-0.001 \\
(0.000)^{\star \star \star}\end{array}$ & $\begin{array}{c}-0.001 \\
(0.001)^{\star \star \star}\end{array}$ & $\begin{array}{c}-0.001 \\
(0.001)^{\star \star \star}\end{array}$ \\
\hline Firm Tenure & $\begin{array}{c}0.008 \\
(0.000)^{\star \star *}\end{array}$ & $\begin{array}{c}0.007 \\
(0.0002)^{\star \star \star}\end{array}$ & & & & \\
\hline Observations & 918,366 & 918,366 & 188,383 & 188,383 & 21,286 & 21,286 \\
\hline R Squared & 0.350 & 0.350 & 0.260 & 0.260 & 0.270 & 0.270 \\
\hline \multicolumn{7}{|l|}{ Panel C: High-Skilled } \\
\hline Task Tenure & & $\begin{array}{c}0.021 \\
(0.001)^{\star \star \star}\end{array}$ & & $\begin{array}{c}0.025 \\
(0.001)^{\star \star \star}\end{array}$ & & $\begin{array}{c}0.023 \\
(0.005)^{\star \star \star}\end{array}$ \\
\hline Occupational Tenure & $\begin{array}{c}0.006 \\
(0.000)^{\star \star \star}\end{array}$ & $\begin{array}{c}0.004 \\
(0.000)^{\star \star \star}\end{array}$ & $\begin{array}{c}0.012 \\
(0.001)^{\star \star \star}\end{array}$ & $\begin{array}{c}0.010 \\
(0.001)^{\star \star \star}\end{array}$ & $\begin{array}{c}0.012 \\
(0.003)^{\star \star \star}\end{array}$ & $\begin{array}{c}0.010 \\
(0.003)^{\star \star \star}\end{array}$ \\
\hline Experience & $\begin{array}{c}0.082 \\
(0.001)^{\star \star \star}\end{array}$ & $\begin{array}{c}0.065 \\
(0.001)^{\star \star \star}\end{array}$ & $\begin{array}{c}0.066 \\
(0.001)^{\star \star \star}\end{array}$ & $\begin{array}{c}0.047 \\
(0.002)^{\star \star \star}\end{array}$ & $\begin{array}{c}0.054 \\
(0.005)^{\star \star \star}\end{array}$ & $\begin{array}{c}0.037 \\
(0.006)^{\star \star \star}\end{array}$ \\
\hline Experience Squared & $\begin{array}{c}-0.003 \\
(0.000)^{\star \star \star}\end{array}$ & $\begin{array}{c}-0.003 \\
(0.000)^{\star \star \star}\end{array}$ & $\begin{array}{c}-0.003 \\
(0.000)^{\star \star \star}\end{array}$ & $\begin{array}{c}-0.002 \\
(0.000)^{\star \star \star}\end{array}$ & $\begin{array}{c}-0.002 \\
(0.000)^{\star \star \star}\end{array}$ & $\begin{array}{c}-0.002 \\
(0.000)^{\star \star \star}\end{array}$ \\
\hline Firm Tenure & $\begin{array}{c}0.009 \\
(0.000)^{\star \star \star}\end{array}$ & $\begin{array}{c}0.007 \\
(0.000)^{\star \star \star}\end{array}$ & & & & \\
\hline Observations & 196,900 & 196,900 & 35,072 & 35,072 & 3,533 & 3,533 \\
\hline Log-Likelihood & -93460.3 & -93134.0 & -14300.1 & -14152.7 & -933.6 & -921.6 \\
\hline
\end{tabular}

Notes: The table reports results from a regression of the log daily wage on general human capital (experience, experience squared), firm tenure, occupation and task tenure. All specifications include year, region and occupation dummies. Panel $\mathrm{C}$ estimates tobit models to account for censoring. Specifications in columns (2), (4) and (6) add our measure of task tenure to the specification in columns (1), (3) and (5). Columns (1)-(2) are estimated for the whole sample, columns (3)-(4) on those who have switched firms and columns (5)-(6) on our sample of displaced workers. Standard errors allow for clustering at the individual level. For Panel C, standard errors are bootstrapped with 100 replications to account for clustering at the individual level. Coefficients with ***, ${ }^{\star *}$, * are significant at the 1,5 and 10 percent level respectively. 
Table 9: Returns to Labor Market Skills: Control Function

\begin{tabular}{|c|c|c|c|c|c|c|}
\hline & \multicolumn{2}{|c|}{$\frac{\text { Control Function }}{\text { Firm Switchers }}$} & \multicolumn{2}{|c|}{$\frac{\text { Control Function }}{\text { Displaced Sample }}$} & \multicolumn{2}{|c|}{$\begin{array}{c}\text { FD/FE } \\
\text { Firm Switchers }\end{array}$} \\
\hline & $(1)$ & $(2)$ & $(3)$ & $(4)$ & $(5)$ & $(6)$ \\
\hline \multicolumn{7}{|l|}{ Panel A: Low-Skilled } \\
\hline Task Tenure & & $\begin{array}{c}0.035 \\
(0.015)^{\star \star}\end{array}$ & & $\begin{array}{c}0.032 \\
(0.0340)\end{array}$ & & $\begin{array}{c}0.007 \\
(0.002)^{\star \star \star}\end{array}$ \\
\hline Occupational Tenure & $\begin{array}{c}-0.001 \\
(0.0030)\end{array}$ & $\begin{array}{c}-0.016 \\
(0.005)^{\star \star}\end{array}$ & $\begin{array}{c}0.008 \\
(0.004)^{\star}\end{array}$ & $\begin{array}{c}-0.007 \\
(0.0140)\end{array}$ & $\begin{array}{c}0.009 \\
(0.001)^{\star \star \star}\end{array}$ & $\begin{array}{c}0.010 \\
(0.001)^{\star \star \star}\end{array}$ \\
\hline Experience & $\begin{array}{c}0.061 \\
(0.002)^{\star \star \star}\end{array}$ & $\begin{array}{c}0.044 \\
(0.018)^{\star \star}\end{array}$ & $\begin{array}{c}0.049 \\
(0.003)^{\star \star \star}\end{array}$ & $\begin{array}{c}0.035 \\
(0.019)^{\star}\end{array}$ & $\begin{array}{c}0.079 \\
(0.009)^{\star \star \star}\end{array}$ & $\begin{array}{c}0.072 \\
(0.009)^{\star \star \star}\end{array}$ \\
\hline Experience Squared & $\begin{array}{c}-0.002 \\
(0.000)^{\star * *}\end{array}$ & $\begin{array}{c}-0.002 \\
(0.000)^{\star * \star}\end{array}$ & $\begin{array}{c}-0.002 \\
(0.000)^{\star * \star}\end{array}$ & $\begin{array}{c}-0.002 \\
(0.000)^{\star \star *}\end{array}$ & $\begin{array}{c}-0.006 \\
(0.000)^{\star \star \star}\end{array}$ & $\begin{array}{c}-0.006 \\
(0.000)^{\star \star \star}\end{array}$ \\
\hline Observations & 56,943 & 56,943 & 7,976 & 7,976 & 56,814 & 56,814 \\
\hline R Squared & 0.31 & 0.32 & 0.35 & 0.36 & 0.060 & 0.060 \\
\hline \multicolumn{7}{|c|}{ Panel B: Medium-Skilled } \\
\hline Task Tenure & & $\begin{array}{c}0.027 \\
(0.007)^{\star \star \star}\end{array}$ & & $\begin{array}{c}0.081 \\
(0.018)^{\star \star \star}\end{array}$ & & $\begin{array}{c}0.007 \\
(0.001)^{\star \star \star}\end{array}$ \\
\hline Occupational Tenure & $\begin{array}{c}0.011 \\
(0.001)^{\star \star \star}\end{array}$ & $\begin{array}{c}-0.002 \\
(0.0030)\end{array}$ & $\begin{array}{c}0.006 \\
(0.001)^{\star \star \star}\end{array}$ & $\begin{array}{c}-0.027 \\
(0.009)^{\star \star \star}\end{array}$ & $\begin{array}{c}0.008 \\
(0.000)^{\star \star \star}\end{array}$ & $\begin{array}{c}0.009 \\
(0.000)^{\star \star \star}\end{array}$ \\
\hline Experience & $\begin{array}{c}0.04 \\
(0.001)^{\star \star \star}\end{array}$ & $\begin{array}{c}0.029 \\
(0.003)^{\star \star \star}\end{array}$ & $\begin{array}{c}0.04 \\
(0.001)^{\star \star \star}\end{array}$ & $\begin{array}{c}0.02 \\
(0.009)^{\star}\end{array}$ & $\begin{array}{c}-0.010 \\
(0.003)^{\star \star \star}\end{array}$ & $\begin{array}{c}-0.018 \\
(0.003)^{\star \star \star}\end{array}$ \\
\hline Experience Squared & $\begin{array}{c}-0.001 \\
(0.000)^{\star \star \star}\end{array}$ & $\begin{array}{c}-0.001 \\
(0.000)^{\star \star \star}\end{array}$ & $\begin{array}{c}-0.001 \\
(0.000)^{\star \star \star}\end{array}$ & $\begin{array}{c}-0.001 \\
(0.000)^{\star \star \star}\end{array}$ & $\begin{array}{c}-0.002 \\
(0.000)^{\star \star \star}\end{array}$ & $\begin{array}{c}-0.002 \\
(0.000)^{\star \star \star}\end{array}$ \\
\hline Observations & 189,435 & 189,435 & 28,137 & 28,137 & 188,381 & 188,381 \\
\hline R Squared & 0.31 & 0.32 & 0.32 & 0.32 & 0.040 & 0.040 \\
\hline \multicolumn{7}{|l|}{ Panel C: High-Skilled } \\
\hline Task Tenure & & $\begin{array}{c}0.068 \\
(0.029)^{\star \star \star}\end{array}$ & & $\begin{array}{l}0.009 \\
(0.0100)\end{array}$ & & $\begin{array}{c}0.053 \\
(0.003)^{\star \star \star}\end{array}$ \\
\hline Occupational Tenure & $\begin{array}{c}-0.014 \\
(0.002)^{\star \star \star}\end{array}$ & $\begin{array}{c}-0.037 \\
(0.010)^{\star \star \star}\end{array}$ & $\begin{array}{c}-0.004 \\
(0.001)^{\star \star \star}\end{array}$ & $\begin{array}{l}-0.010 \\
(0.028)\end{array}$ & $\begin{array}{c}0.006 \\
(0.000)^{\star \star}\end{array}$ & $\begin{array}{c}-0.006 \\
(0.001)^{\star \star \star}\end{array}$ \\
\hline Experience & $\begin{array}{c}0.127 \\
(0.002)^{\star \star \star}\end{array}$ & $\begin{array}{c}0.091 \\
(0.022)^{\star \star \star}\end{array}$ & $\begin{array}{c}0.109 \\
(0.003)^{\star \star \star}\end{array}$ & $\begin{array}{c}0.126 \\
(0.017)^{\star \star \star}\end{array}$ & $\begin{array}{c}0.082 \\
(0.001)^{\star \star}\end{array}$ & $\begin{array}{c}0.033 \\
(0.002)^{\star \star \star}\end{array}$ \\
\hline Experience Squared & $\begin{array}{c}-0.007 \\
(0.000)^{\star \star \star}\end{array}$ & $\begin{array}{c}-0.008 \\
(0.000)^{\star \star \star}\end{array}$ & $\begin{array}{c}-0.006 \\
(0.000)^{\star \star \star}\end{array}$ & $\begin{array}{c}-0.008 \\
(0.001)^{\star \star \star}\end{array}$ & $\begin{array}{c}-0.003 \\
(0.000)^{\star \star}\end{array}$ & $\begin{array}{c}-0.003 \\
(0.000)^{\star \star \star}\end{array}$ \\
\hline Observations & 30,376 & 30,376 & 3,065 & 3,065 & 35,072 & 35,072 \\
\hline $\begin{array}{l}\text { Note: For the medium- } \\
\text { have switched firms (co } \\
\text { report first difference es } \\
\text { semiparametric estimatc } \\
\text { regressors. Columns ( } 5 \\
\text { models. In all specificati } \\
\text { level. All specifications } \\
\text { results of the high-skillec } \\
\text { significant at the } 1,5 \text { and }\end{array}$ & $\begin{array}{l}\mathrm{d}(\text { Panel } \mathrm{A} \text { al } \\
\text { (2)) and ou } \\
\text { the sample } \\
\text { by Blundell } \\
\text { w fixed effe }\end{array}$ & $\begin{array}{l}\text { ), columns } \\
\text { imple of di } \\
\text { rm switche } \\
\text { Powell (2 } \\
\text { estimates }\end{array}$ & $\begin{array}{l}\text { to (4) repor } \\
\text { ced workers } \\
\text { or the high } \\
\text { to accour }\end{array}$ & $\begin{array}{l}\text { umns }(3) \\
\text { d (Panel } \\
\text { censorin }\end{array}$ & $\begin{array}{l}\text { olumns ( } \\
\text { addition } \\
\text { nming pro }\end{array}$ & $\begin{array}{l}\text { for those who } \\
\text { s (5) and }(6, \\
\text { o (4) report a } \\
\text { endogenous } \\
\text { dure for tobi } \\
\text { the individua } \\
\text { metric model } \\
h^{* \star *},{ }^{* \star},{ }^{*} \text { are }\end{array}$ \\
\hline
\end{tabular}


Figure 1: Quarterly Occupation Quit Rate by Time in the Labor Market

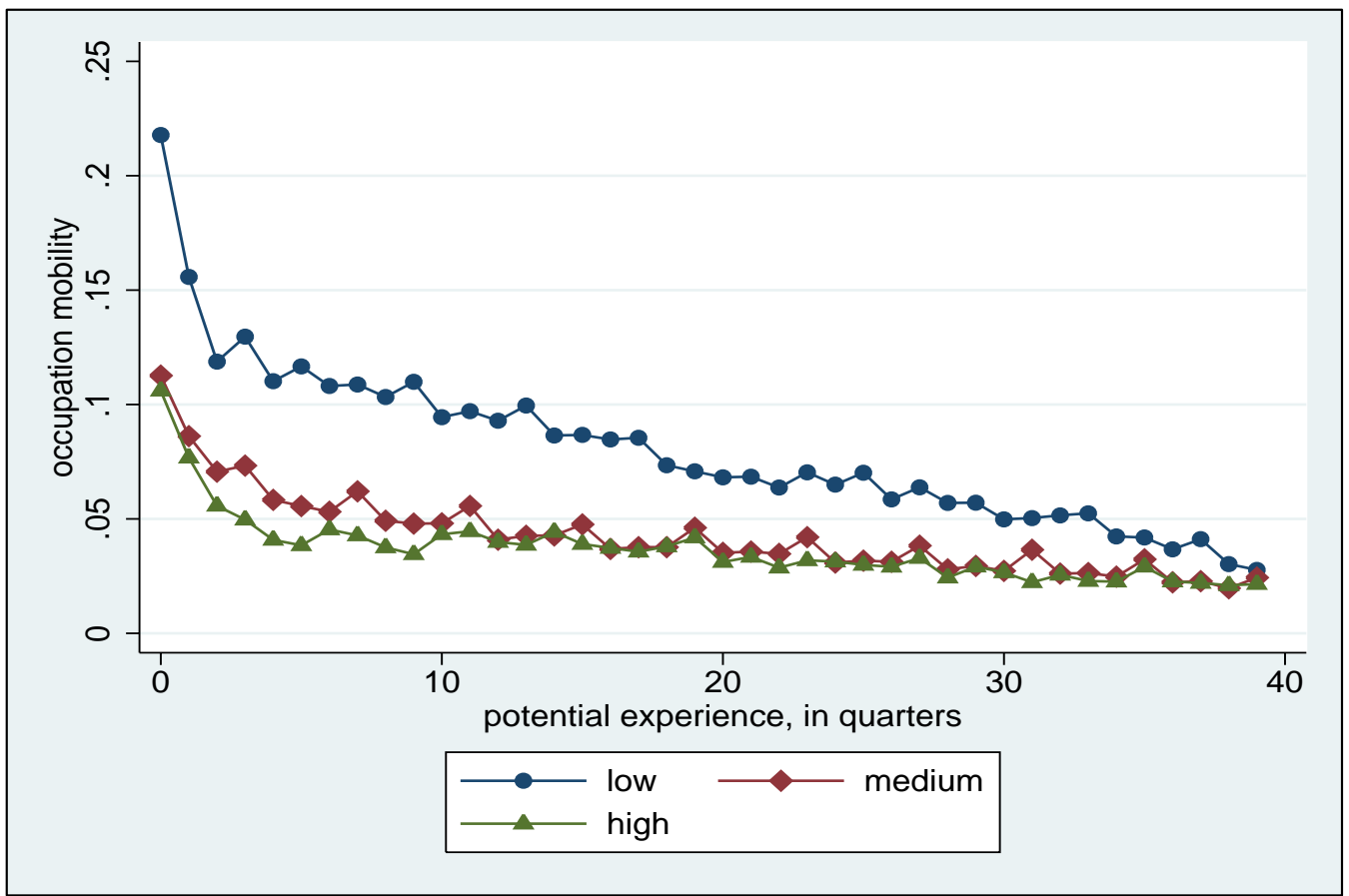

Notes: The figure shows the quarterly occupation quit rate by education and time in the labor market (potential experience). Quit rates are defined over the sample of workers who are employed at the beginning of the quarter. 
Figure 2: Observed Mobility is More Similar Than Random Mobility

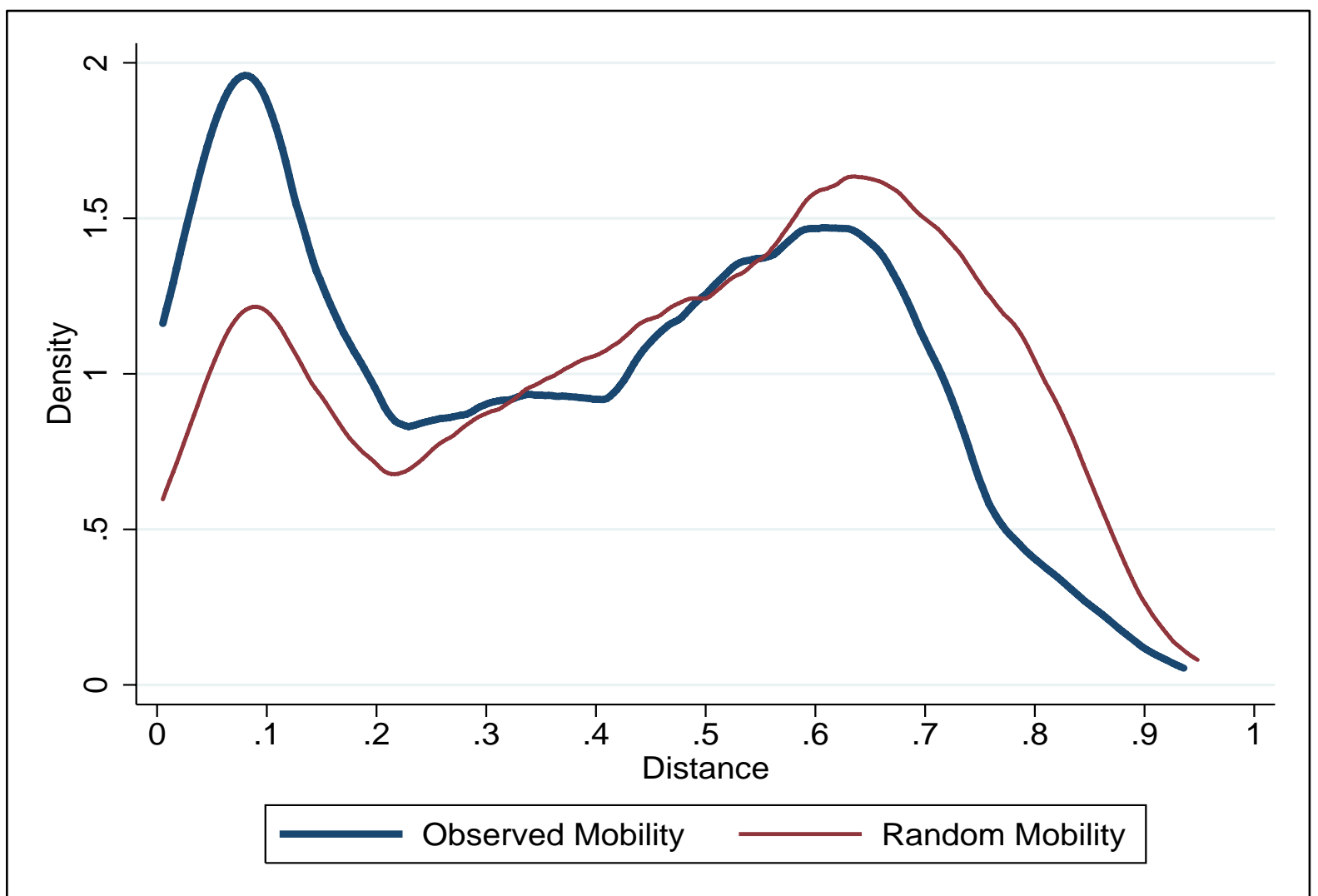

Notes: The figure plots the density of the distance measure under observed and random mobility. We calculate random mobility as follows: for each mover, we assume that the probability of going to any other occupation in the data is solely determined by the relative size of the target occupation. We then multiply this "random move" with its distance to get the distribution of the distance measure under random mobility. Distance measure: angular separation, 19 tasks. 
Figure 3: Distance of Occupational Moves Declines over Career

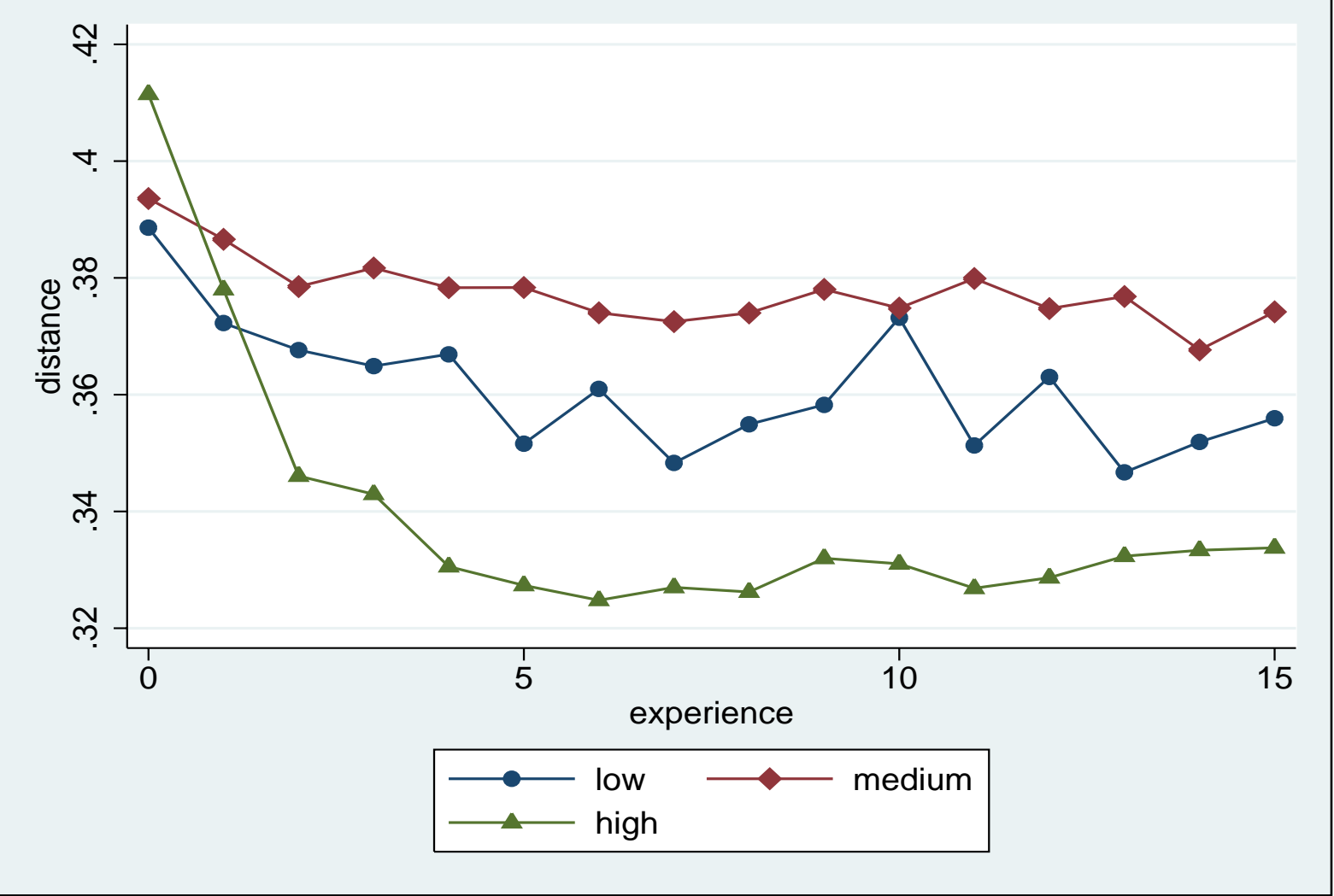

Notes: The figure plots the average distance of the occupational move by actual experience. Regressions control for 15 experience dummies, occupation dummies, and time dummies. The decline in the average distance by experience is significant at a $1 \%$ level for all education groups. Distance measure: angular separation based on 19 tasks. 
Figure 4a: Correlation of Wages by Distance of Move

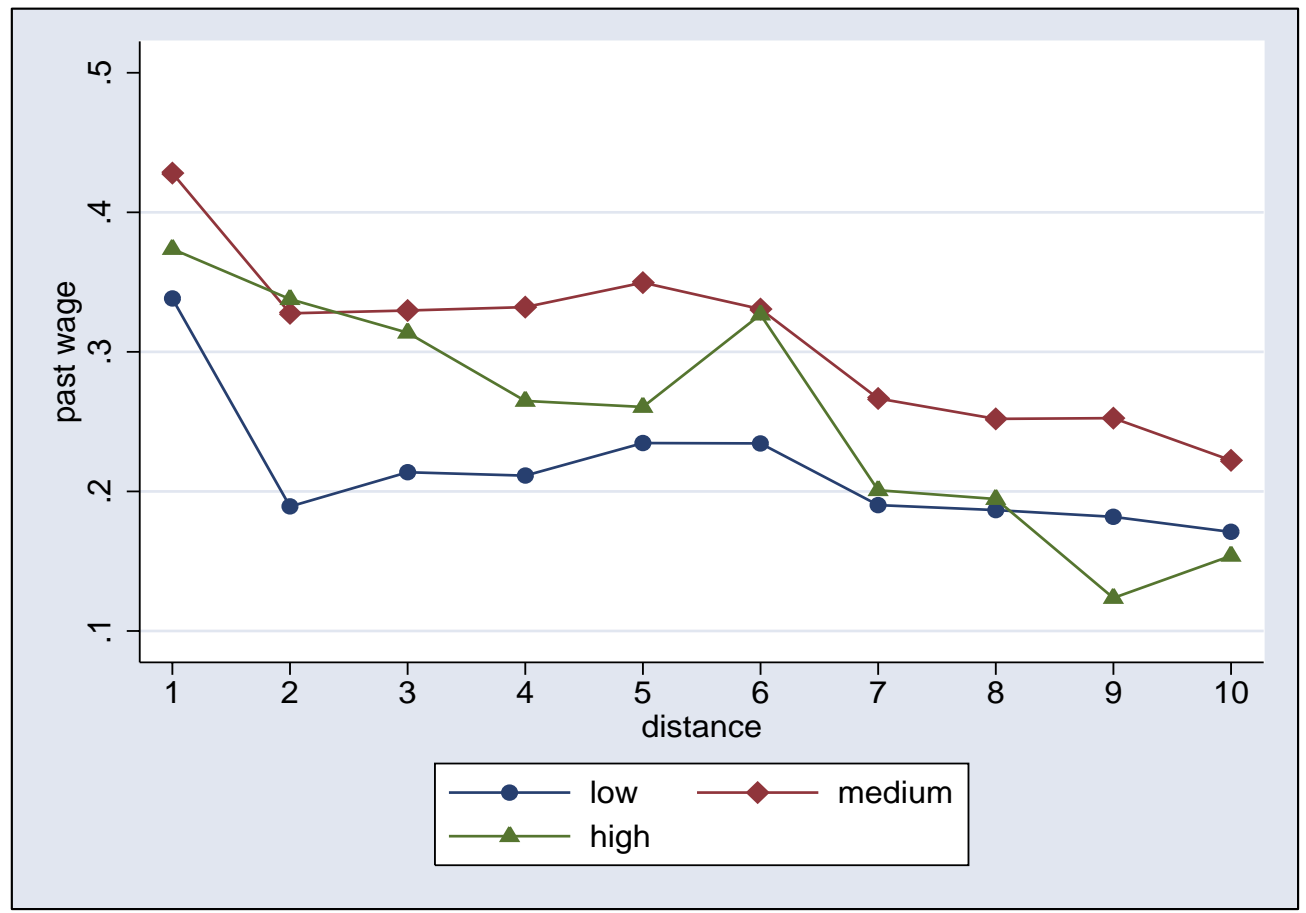

Figure 4b: Impact of Past Occupational Tenure by Distance of Move

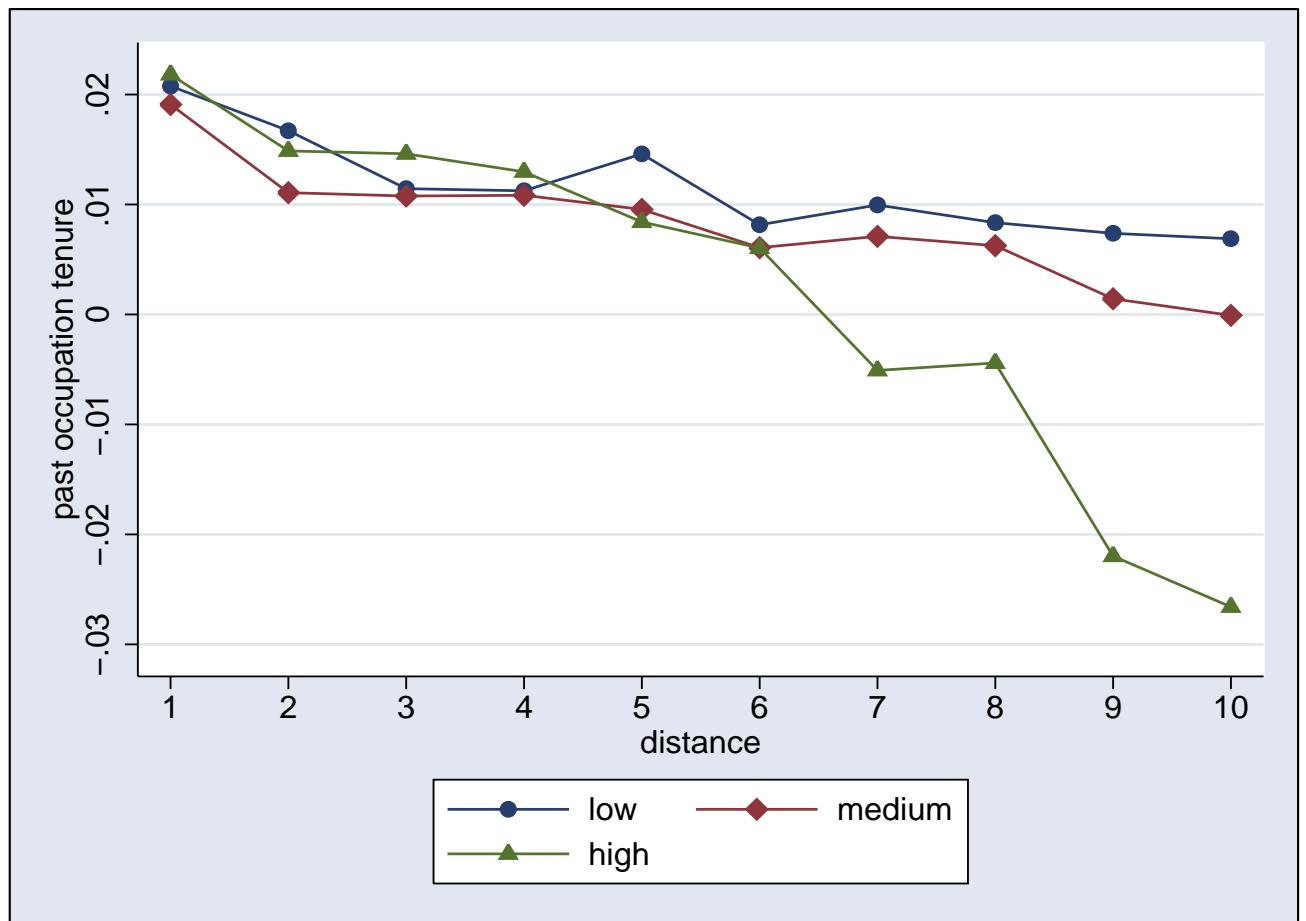

Notes: The upper panel plots the impact of the past wage on the current wage by the distance of the occupational move. Regressions control for occupation and time dummies, past wages, ten distance dummies as well as the past wage interacted with the 10 distance dummies. The lower panel plots the impact of past occupation tenure on current wages by the distance of the occupational move. Regressions control for occupation and time dummies, past occupation tenure and past occupation tenure interacted with ten distance dummies. 
Table A1: List of Occupations and Task Usage

\begin{tabular}{|c|c|c|c|c|}
\hline Title of Occupation & Employed (\%) & Manual Tasks & Analytic Tasks & Interactive Tasks \\
\hline Miners, Stone-Breaker, Mineral Processing & 0.91 & 0.975 & 0.256 & 0.280 \\
\hline Concrete and Cement Finishers, Stone Processing & 0.36 & 0.995 & 0.363 & 0.365 \\
\hline Potter, Ceramicist, Gaffer & 0.36 & 0.957 & 0.481 & 0.319 \\
\hline Chemical Processing & 1.65 & 0.965 & 0.575 & 0.397 \\
\hline Plastics and Polymer Processing & 1.14 & 0.972 & 0.462 & 0.395 \\
\hline Paper and Pulp Processing & 0.68 & 0.961 & 0.556 & 0.493 \\
\hline Printer, Typesetter, Typographer & 0.83 & 0.911 & 0.587 & 0.458 \\
\hline Wood, Lumber and Timber Processing & 0.46 & 0.866 & 0.343 & 0.230 \\
\hline Metal and Iron Manufacturer & 0.41 & 0.974 & 0.364 & 0.281 \\
\hline Moulding, Shaping & 0.38 & 0.928 & 0.366 & 0.224 \\
\hline Metal Presser and Moulder & 0.54 & 0.998 & 0.391 & 0.230 \\
\hline Metal Polisher, Sanders, Buffers, Lathe Operators & 2.26 & 0.988 & 0.483 & 0.319 \\
\hline Welder, Brazing, Soldering & 0.51 & 0.952 & 0.331 & 0.217 \\
\hline Blacksmith, Farrier, Forger, Plumber and Pipe Fitters & 3.24 & 0.977 & 0.525 & 0.498 \\
\hline Locksmith & 6.23 & 0.977 & 0.452 & 0.361 \\
\hline Mechanic, Machinist, Repairmen & 4.26 & 0.971 & 0.566 & 0.469 \\
\hline Tool and Dye Maker, Instrument Mechanic & 1.29 & 0.980 & 0.569 & 0.443 \\
\hline Metal Craftsmen & 0.34 & 0.959 & 0.698 & 0.568 \\
\hline Electricians, Electrical Installation & 5.49 & 0.965 & 0.639 & 0.516 \\
\hline Assembler & 2.75 & 0.904 & 0.348 & 0.240 \\
\hline Weaver, Spinner, Knitters, Wool Trade & 0.13 & 0.974 & 0.326 & 0.343 \\
\hline Tailor, Textile Worker & 0.19 & 0.911 & 0.346 & 0.270 \\
\hline Shoemaker & 0.22 & 0.906 & 0.316 & 0.483 \\
\hline Baker & 1.00 & 0.963 & 0.396 & 0.500 \\
\hline Butcher & 1.02 & 0.895 & 0.351 & 0.470 \\
\hline Cook & 1.21 & 0.918 & 0.449 & 0.648 \\
\hline Beverage Production, Milk Production, Grease Processing & 0.47 & 0.916 & 0.563 & 0.462 \\
\hline Bricklayer, Mason & 2.52 & 0.933 & 0.335 & 0.373 \\
\hline Carpenter & 1.61 & 0.957 & 0.387 & 0.417 \\
\hline Road Builder & 0.79 & 0.915 & 0.292 & 0.309 \\
\hline Unskilled Construction Worker & 1.24 & 0.893 & 0.167 & 0.168 \\
\hline Plasterer & 1.09 & 0.935 & 0.403 & 0.407 \\
\hline Interior Decorator, Interior Designer & 0.31 & 0.943 & 0.471 & 0.532 \\
\hline Joiner, Cabinet Maker & 2.85 & 0.972 & 0.501 & 0.440 \\
\hline Painters & 2.20 & 0.909 & 0.327 & 0.412 \\
\hline Product Tester & 1.70 & 0.697 & 0.575 & 0.392 \\
\hline Unskilled Worker & 1.69 & 0.903 & 0.303 & 0.198 \\
\hline Crane Driver, Crane Operator, Skinner, Machine Operator & 0.91 & 0.982 & 0.466 & 0.366 \\
\hline Engineers & 3.64 & 0.526 & 0.934 & 0.859 \\
\hline Chemist, Physicist, & 4.46 & 0.717 & 0.883 & 0.807 \\
\hline Technical Service Personel & 1.05 & 0.538 & 0.920 & 0.551 \\
\hline Sales Personnel & 4.90 & 0.572 & 0.695 & 0.958 \\
\hline Banker & 2.97 & 0.425 & 0.844 & 0.930 \\
\hline Traders, Trading Personnel & 0.77 & 0.516 & 0.791 & 0.891 \\
\hline Truck Driver, Conductor & 3.99 & 0.852 & 0.230 & 0.351 \\
\hline Sailor, Seaman, Navigator, Mariner & 0.12 & 0.849 & 0.528 & 0.659 \\
\hline Mail Carrier and Handlers, Postal Clerks & 0.47 & 0.784 & 0.406 & 0.395 \\
\hline Storekeeper, Warehouse Keeper & 4.57 & 0.823 & 0.354 & 0.388 \\
\hline Entrepreneurs & 1.64 & 0.510 & 0.885 & 0.973 \\
\hline Politicians, Member of Parliament & 0.26 & 0.452 & 0.924 & 0.908 \\
\hline Accountant, Book Keeper & 2.23 & 0.536 & 0.924 & 0.797 \\
\hline Office Clerk & 6.21 & 0.432 & 0.823 & 0.785 \\
\hline Guards, Watchmen, Police, Security Personnel & 1.08 & 0.809 & 0.575 & 0.620 \\
\hline Publicist, Journalist, Authors & 0.17 & 0.403 & 0.841 & 0.866 \\
\hline Musicians & 0.41 & 0.625 & 0.680 & 0.735 \\
\hline Physicians & 0.51 & 0.850 & 0.642 & 0.708 \\
\hline Nurses, Dietitians, Physical Therapists & 0.76 & 0.964 & 0.624 & 0.687 \\
\hline Social Worker & 0.58 & 0.754 & 0.693 & 0.934 \\
\hline Teacher (except university) & 0.91 & 0.474 & 0.697 & 0.964 \\
\hline Scientist, Clergymen & 0.84 & 0.414 & 0.848 & 0.897 \\
\hline Personal Hygiene Technician & 0.12 & 0.898 & 0.388 & 0.750 \\
\hline Waiter, Barkeeper, Innkeeper & 0.64 & 0.919 & 0.352 & 0.737 \\
\hline Janitor, Home Economics, Housekeeper & 0.03 & 0.616 & 0.649 & 0.804 \\
\hline Cleaning Service Workers & 1.04 & 0.848 & 0.243 & 0.247 \\
\hline Mean & & 0.8028 & 0.5628 & 0.5464 \\
\hline
\end{tabular}

Notes: The table shows the title of the 64 occupations, the percentage of individuals employed in it and the fraction of individuals that report performing analytical, manual and interactive tasks on their job following the classification of Autor et al (2003). For a description of the tasks underlying the three aggregate task groups, see Table B2.

Source : IAB Employee Sample, matched with Qualification and Career Survey: 1979, 1985, 1991/2, 1997/8. 
Table A2: Estimates of Reduced Forms for Control Function Estimator (Table 9)

\begin{tabular}{|c|c|c|c|c|c|c|c|c|c|c|c|c|}
\hline & \multicolumn{6}{|c|}{$\underline{\text { Panel A: Low Skilled }}$} & \multicolumn{6}{|c|}{ Panel B: Medium Skilled } \\
\hline & \multicolumn{3}{|c|}{ Starting New Job } & \multicolumn{3}{|c|}{ Displaced Sample } & \multicolumn{3}{|c|}{ Starting New Job } & \multicolumn{3}{|c|}{ Displaced Sample } \\
\hline & $\begin{array}{c}\text { Actual } \\
\text { Experience } \\
(1) \\
\end{array}$ & $\begin{array}{c}\text { Occupation } \\
\text { Tenure } \\
\text { (2) } \\
\end{array}$ & $\begin{array}{c}\text { Task } \\
\text { Tenure } \\
(3) \\
\end{array}$ & $\begin{array}{c}\text { Actual } \\
\text { Experience } \\
(4) \\
\end{array}$ & $\begin{array}{c}\text { Occupation } \\
\text { Tenure } \\
\text { (5) } \\
\end{array}$ & $\begin{array}{c}\text { Task } \\
\text { Tenure } \\
(6) \\
\end{array}$ & $\begin{array}{c}\text { Actual } \\
\text { Experience } \\
(1) \\
\end{array}$ & $\begin{array}{c}\text { Occupation } \\
\text { Tenure } \\
\text { (2) } \\
\end{array}$ & $\begin{array}{c}\text { Task } \\
\text { Tenure } \\
(3) \\
\end{array}$ & $\begin{array}{c}\text { Actual } \\
\text { Experience } \\
(4) \\
\end{array}$ & $\begin{array}{c}\text { Occupation } \\
\text { Tenure } \\
\text { (5) } \\
\end{array}$ & $\begin{array}{c}\text { Task } \\
\text { Tenure } \\
(6) \\
\end{array}$ \\
\hline Age & $\begin{array}{c}0.047 \\
(0.025)^{*}\end{array}$ & $\begin{array}{c}0.099 \\
(0.022)^{\star \star \star}\end{array}$ & $\begin{array}{c}-0.069 \\
(0.021)^{\star \star \star}\end{array}$ & $\begin{array}{c}0.296 \\
(0.072)^{\star \star \star}\end{array}$ & $\begin{array}{c}0.258 \\
(0.066)^{\star \star \star}\end{array}$ & $\begin{array}{c}0.168 \\
(0.066)^{\star \star}\end{array}$ & $\begin{array}{c}0.005 \\
-0.014\end{array}$ & $\begin{array}{c}0.125 \\
(0.014)^{\star \star \star}\end{array}$ & $\begin{array}{c}0.050 \\
(0.015)^{\star \star \star}\end{array}$ & $\begin{array}{c}0.114 \\
(0.037)^{\star \star \star}\end{array}$ & $\begin{array}{c}0.200 \\
(0.037)^{\star \star \star}\end{array}$ & $\begin{array}{c}0.186 \\
(0.042)^{\star \star \star}\end{array}$ \\
\hline Age Squared & $\begin{array}{c}0.011 \\
(0.000)^{\star \star \star}\end{array}$ & $\begin{array}{c}0.007 \\
(0.000)^{\star \star \star}\end{array}$ & $\begin{array}{c}0.004 \\
(0.000)^{\star \star \star}\end{array}$ & $\begin{array}{c}0.008 \\
(0.001)^{\star \star \star}\end{array}$ & $\begin{array}{c}0.005 \\
(0.001)^{\star \star \star}\end{array}$ & $\begin{array}{c}0.001 \\
(0.001)\end{array}$ & $\begin{array}{c}0.013 \\
(0.000)^{\star \star \star}\end{array}$ & $\begin{array}{c}0.008 \\
(0.000)^{\star \star \star}\end{array}$ & $\begin{array}{c}0.004 \\
(0.000)^{\star \star \star}\end{array}$ & $\begin{array}{c}0.011 \\
(0.001)^{\star \star \star}\end{array}$ & $\begin{array}{c}0.006 \\
(0.001)^{\star \star \star}\end{array}$ & $\begin{array}{c}0.002 \\
(0.001)^{\star \star \star}\end{array}$ \\
\hline Mean Distance to Other Occupations & $\begin{array}{l}-0.627 \\
(0.433)\end{array}$ & $\begin{array}{c}3.596 \\
(0.386)^{\star \star \star}\end{array}$ & $\begin{array}{c}-1.596 \\
(0.364)^{\star \star \star}\end{array}$ & $\begin{array}{c}2.090 \\
(1.171)^{\star}\end{array}$ & $\begin{array}{c}4.744 \\
(1.073)^{\star \star \star}\end{array}$ & $\begin{array}{c}-1.881 \\
(1.075)^{\star}\end{array}$ & $\begin{array}{c}1.180 \\
(0.235)^{\star \star \star}\end{array}$ & $\begin{array}{c}5.447 \\
(0.237)^{\star \star \star}\end{array}$ & $\begin{array}{c}-0.606 \\
(0.258)^{\star \star}\end{array}$ & $\begin{array}{c}1.028 \\
(0.608)^{\star}\end{array}$ & $\begin{array}{c}3.882 \\
(0.622)^{\star \star \star}\end{array}$ & $\begin{array}{l}-0.670 \\
(0.691)\end{array}$ \\
\hline Age*Mean Distance & $\begin{array}{c}0.026 \\
(0.017)\end{array}$ & $\begin{array}{c}-0.166 \\
(0.015)^{\star \star \star}\end{array}$ & $\begin{array}{c}0.077 \\
(0.014)^{\star \star \star}\end{array}$ & $\begin{array}{c}-0.083 \\
(0.045)^{\star}\end{array}$ & $\begin{array}{c}-0.209 \\
(0.041)^{\star \star \star}\end{array}$ & $\begin{array}{c}0.059 \\
(0.041)\end{array}$ & $\begin{array}{c}-0.035 \\
(0.009)^{\star \star \star}\end{array}$ & $\begin{array}{c}-0.218 \\
(0.009)^{\star \star \star}\end{array}$ & $\begin{array}{c}0.062 \\
(0.010)^{\star \star \star}\end{array}$ & $\begin{array}{c}-0.037 \\
(0.023)^{*}\end{array}$ & $\begin{array}{c}-0.174 \\
(0.023)^{\star \star \star}\end{array}$ & $\begin{array}{c}0.039 \\
(0.026)\end{array}$ \\
\hline Size of Occupation & $\begin{array}{c}2.035 \\
(2.456)\end{array}$ & $\begin{array}{c}4.513 \\
(2.187)^{\star \star}\end{array}$ & $\begin{array}{c}0.970 \\
(2.065)\end{array}$ & $\begin{array}{c}8.427 \\
(7.122)\end{array}$ & $\begin{array}{c}6.041 \\
(6.524)\end{array}$ & $\begin{array}{l}-0.317 \\
(6.538)\end{array}$ & $\begin{array}{c}-9.828 \\
(1.238)^{\star \star \star}\end{array}$ & $\begin{array}{c}-6.870 \\
(1.246)^{\star \star \star}\end{array}$ & $\begin{array}{c}2.948 \\
(1.356)^{\star \star}\end{array}$ & $\begin{array}{c}-12.458 \\
(3.324)^{\star \star \star}\end{array}$ & $\begin{array}{c}-13.680 \\
(3.399)^{\star \star \star}\end{array}$ & $\begin{array}{l}-1.813 \\
(3.781)\end{array}$ \\
\hline Age ${ }^{\star}$ Size of Occupation & $\begin{array}{l}-0.079 \\
(0.094)\end{array}$ & $\begin{array}{c}-0.168 \\
(0.084)^{\star \star}\end{array}$ & $\begin{array}{c}0.048 \\
(0.079)\end{array}$ & $\begin{array}{c}-0.468 \\
(0.267)^{\star}\end{array}$ & $\begin{array}{c}-0.252 \\
(0.244)\end{array}$ & $\begin{array}{c}0.072 \\
(0.245)\end{array}$ & $\begin{array}{c}0.414 \\
(0.045)^{\star \star \star}\end{array}$ & $\begin{array}{c}0.361 \\
(0.045)^{\star \star \star}\end{array}$ & $\begin{array}{r}0.005 \\
-0.049\end{array}$ & $\begin{array}{c}0.498 \\
(0.119)^{\star \star \star}\end{array}$ & $\begin{array}{c}0.574 \\
(0.121)^{\star \star \star}\end{array}$ & $\begin{array}{c}0.145 \\
(0.135)\end{array}$ \\
\hline Deviation from Occupation Tenure & $\begin{array}{c}0.160 \\
(0.006)^{\star \star \star}\end{array}$ & $\begin{array}{c}0.306 \\
(0.006)^{\star \star \star}\end{array}$ & $\begin{array}{c}0.570 \\
(0.005)^{\star \star \star}\end{array}$ & $\begin{array}{c}0.258 \\
(0.017)^{\star \star \star}\end{array}$ & $\begin{array}{c}0.455 \\
(0.016)^{\star \star \star}\end{array}$ & $\begin{array}{c}0.800 \\
(0.016)^{\star \star \star}\end{array}$ & $\begin{array}{c}0.193 \\
(0.002)^{\star \star \star}\end{array}$ & $\begin{array}{c}0.381 \\
(0.002)^{\star \star \star}\end{array}$ & $\begin{array}{c}0.656 \\
(0.003)^{\star \star \star}\end{array}$ & $\begin{array}{c}0.263 \\
(0.006)^{\star \star \star}\end{array}$ & $\begin{array}{c}0.485 \\
(0.006)^{\star \star \star}\end{array}$ & $\begin{array}{c}0.791 \\
(0.007)^{\star \star \star}\end{array}$ \\
\hline Year Dummies & Yes & Yes & Yes & Yes & Yes & Yes & Yes & Yes & Yes & Yes & Yes & Yes \\
\hline Occupation Dummies & Yes & Yes & Yes & Yes & Yes & Yes & Yes & Yes & Yes & Yes & Yes & Yes \\
\hline Regional Dummies & Yes & Yes & Yes & Yes & Yes & Yes & Yes & Yes & Yes & Yes & Yes & Yes \\
\hline Observations & 56,943 & 56,943 & 56,943 & 7,976 & 7,976 & 7,976 & 189,435 & 189,435 & 189,435 & 28,137 & 28,137 & 28,137 \\
\hline R Squared & 0.65 & 0.58 & 0.36 & 0.69 & 0.63 & 0.47 & 0.75 & 0.66 & 0.50 & 0.76 & 0.69 & 0.58 \\
\hline
\end{tabular}

Notes: The table reports the regression results of the reduced forms for experience, occupational tenure and task tenure used to construct the control function in Table 9 , for the low- and medium-skilled. All specifications are estimated on the sample of firm switchers in columns (1) to (3) and on the sample of displaced workers in columns (4) to (6). For each education group, the dependent variable is experience (columns (1) and (4)), occupational tenure (columns (2) and (5)) and task tenure (columns (3) and (6)) respectively. All specifications include occupation, year and region dummies. Coefficients with ***, **, * are significant at the 1,5 and 10 percent level respectively. See also notes to Table 9. 


\section{Table A3: First- and Second-Stage Regression of Control Variable Estimator for Models with Censoring}

\begin{tabular}{|c|c|c|c|c|c|c|c|c|c|c|}
\hline & \multicolumn{10}{|c|}{ Panel C: High Skilled } \\
\hline & \multicolumn{5}{|c|}{ Starting New Job } & \multicolumn{5}{|c|}{ Displaced Sample } \\
\hline & $\begin{array}{c}\text { Actual } \\
\text { Experience } \\
(1) \\
\end{array}$ & $\begin{array}{c}\text { Experience } \\
\text { Squared } \\
(2)\end{array}$ & $\begin{array}{l}\text { Occupation } \\
\text { Tenure } \\
\text { (3) } \\
\end{array}$ & $\begin{array}{c}\text { Task } \\
\text { Tenure } \\
(4)\end{array}$ & $\begin{array}{c}\text { Log } \\
\text { Wage } \\
(5) \\
\end{array}$ & $\begin{array}{c}\text { Actual } \\
\text { Experience } \\
(6) \\
\end{array}$ & $\begin{array}{c}\text { Experience } \\
\text { Squared } \\
(7)\end{array}$ & $\begin{array}{l}\text { Occupation } \\
\text { Tenure } \\
(8) \\
\end{array}$ & $\begin{array}{c}\text { Task } \\
\text { Tenure } \\
(9)\end{array}$ & $\begin{array}{l}\text { Log } \\
\text { Wage } \\
(10) \\
\end{array}$ \\
\hline \multirow[t]{2}{*}{ Age } & -0.435 & -29.961 & -0.422 & -0.336 & 0.082 & -0.184 & -26.754 & -0.179 & -0.181 & 0.0742 \\
\hline & $(0.034)^{\star \star \star}$ & $(0.577)^{\star \star \star}$ & $(0.031)^{\star \star \star}$ & $(0.030)^{\star \star *}$ & $(0.0064)^{\star \star \star}$ & -0.123 & $(2.281)^{\star \star \star}$ & $(0.105)^{\star}$ & -0.111 & $(0.0000)^{\star * \star}$ \\
\hline \multirow[t]{2}{*}{ Age Squared } & 0.017 & 0.606 & 0.014 & 0.009 & -0.001 & 0.014 & 0.578 & 0.006 & 0.012 & -0.0009 \\
\hline & $(0.000)^{\star * \star}$ & $(0.008)^{\star \star \star}$ & $(0.000)^{\star \star \star}$ & $(0.000)^{\star \star \star}$ & $(0.0001)^{\star \star \star}$ & $(0.002)^{\star \star \star}$ & $(0.031)^{\star * \star}$ & $(0.001)^{\star \star \star}$ & $(0.002)^{\star \star \star}$ & $(0.0000)^{\star \star \star}$ \\
\hline \multirow[t]{2}{*}{ Mean Distance to Other Occupations } & 2.120 & 63.892 & 2.339 & -1.861 & 0.139 & 5.292 & 81.816 & 0.842 & 6.882 & 0.2156 \\
\hline & $(0.675)^{\star \star \star}$ & $(11.611)^{\star \star \star}$ & $(0.620)^{\star \star *}$ & $(0.610)^{\star \star \star}$ & $(0.119)$ & $(2.460)^{\star \star}$ & $(45.447)^{\star}$ & -2.099 & $(2.217)^{\star \star \star}$ & $(0.0000)^{\star \star \star}$ \\
\hline \multirow[t]{2}{*}{ Age*Mean Distance } & -0.111 & -2.244 & -0.094 & 0.101 & -0.004 & -0.177 & -2.908 & 0.047 & -0.202 & -0.0136 \\
\hline & $(0.021)^{\star \star \star}$ & $(0.361)^{\star \star \star}$ & $(0.019)^{\star \star \star}$ & $(0.019)^{\star \star \star}$ & $(0.004)$ & $(0.076)^{\star \star}$ & $(1.402)^{\star \star}$ & -0.065 & $(0.068)^{\star \star \star}$ & $(0.0000)^{\star \star \star}$ \\
\hline \multirow[t]{2}{*}{ Size of Occupation } & -8.088 & -485.684 & -8.408 & 5.456 & 0.259 & 10.534 & 111.336 & -9.332 & 17.506 & 0.3309 \\
\hline & $(3.499)^{\star \star}$ & $(60.167)^{\star \star \star}$ & $(3.211)^{\star \star \star}$ & $(3.163)^{\star}$ & $(0.618)$ & -13.753 & -254.034 & -11.735 & -12.393 & $(0.0000)^{\star \star \star}$ \\
\hline \multirow[t]{2}{*}{ Age ${ }^{\star S i z e ~ o f ~ O c c u p a t i o n ~}$} & 0.440 & 17.425 & 0.431 & -0.090 & -0.002 & -0.357 & -4.613 & 0.303 & -0.545 & -0.0024 \\
\hline & $(0.109)^{\star \star \star}$ & $(1.871)^{\star \star \star}$ & $(0.100)^{\star \star \star}$ & -0.098 & $(0.019)$ & -0.419 & -7.738 & -0.357 & -0.377 & $(0.0000)^{\star \star \star}$ \\
\hline \multirow[t]{2}{*}{ Deviation from Occupation Tenure } & 0.284 & 4.109 & 0.443 & 0.819 & -0.014 & 0.325 & 4.51 & 0.999 & 0.528 & -0.0072 \\
\hline & $(0.007)^{\star \star \star}$ & $(0.118)^{\star \star \star}$ & $(0.006)^{\star \star \star}$ & $(0.006)^{\star \star \star}$ & $(0.0016)^{\star \star \star}$ & $(0.025)^{\star \star \star}$ & $(0.463)^{\star \star \star}$ & $(0.021)^{\star \star \star}$ & $(0.023)^{\star \star \star}$ & $(0.0000)^{\star \star \star}$ \\
\hline \multirow[t]{2}{*}{ Experience } & & & & & 0.0197 & & & & & 0.0235 \\
\hline & & & & & $(0.0024)^{\star \star \star}$ & & & & & $(0.0000)^{\star * *}$ \\
\hline \multirow[t]{2}{*}{ Experience Squared } & & & & & -0.0014 & & & & & -0.0015 \\
\hline & & & & & $(0.0001)^{\star \star \star}$ & & & & & $(0.0000)^{\star \star *}$ \\
\hline \multirow[t]{2}{*}{ Occupational Tenure } & & & & & 0.01 & & & & & 0.0073 \\
\hline & & & & & $(0.0011)^{\star \star \star}$ & & & & & $(0.0000)^{\star \star \star}$ \\
\hline \multirow[t]{2}{*}{ Task Tenure } & & & & & 0.0172 & & & & & 0.0151 \\
\hline & & & & & $(0.0019)^{\star \star \star}$ & & & & & $(0.0000)^{\star \star \star}$ \\
\hline Year Dummies & Yes & Yes & Yes & Yes & Yes & Yes & Yes & Yes & Yes & Yes \\
\hline Occupation Dummies & Yes & Yes & Yes & Yes & Yes & Yes & Yes & Yes & Yes & Yes \\
\hline Regional Dummies & Yes & Yes & Yes & Yes & Yes & Yes & Yes & Yes & Yes & Yes \\
\hline Observations & 34,794 & 34,794 & 34,794 & 34,794 & 34,794 & 3533 & 3533 & 3533 & 3533 & 3533 \\
\hline R Squared & 0.68 & 0.65 & 0.66 & 0.57 & & 0.68 & 0.63 & 0.62 & 0.68 & \\
\hline
\end{tabular}

Notes: For the high-skilled, the table reports the regression of experience, occupational tenure and task tenure on the instruments in columns (7)-(9). In column (10), it reports the results of a quantile regression of the log wage on the instruments and endogenous controls. All specifications include year, occupation and region dummies. See also notes to Table 9 and the Appendix. 
Table A4: Impact of Residuals on Wage Equation (Table 9)

\begin{tabular}{|c|c|c|c|c|c|c|c|c|}
\hline & \multicolumn{4}{|c|}{ Panel A: Low Skilled } & \multicolumn{4}{|c|}{ Panel B: Medium Skilled } \\
\hline & $(1)$ & $(2)$ & $(3)$ & $(4)$ & $(1)$ & $(2)$ & $(3)$ & $(4)$ \\
\hline Residual Experience & $\begin{array}{c}-0.031 \\
(0.002)^{\star \star \star}\end{array}$ & $\begin{array}{c}-0.044 \\
(0.009)^{\star \star \star}\end{array}$ & $\begin{array}{c}-0.018 \\
(0.006)^{\star \star \star}\end{array}$ & $\begin{array}{l}-0.019 \\
(0.035)\end{array}$ & $\begin{array}{c}-0.015 \\
(0.002)^{\star \star \star}\end{array}$ & $\begin{array}{c}-0.031 \\
(0.004)^{\star \star \star}\end{array}$ & $\begin{array}{c}-0.01 \\
(0.002)^{\star \star \star}\end{array}$ & $\begin{array}{c}0.015 \\
(0.011)\end{array}$ \\
\hline Exp. Res. ${ }^{*}$ Experience & $\begin{array}{c}0.003 \\
(0.001)^{\star \star \star}\end{array}$ & $\begin{array}{c}0.008 \\
(0.001)^{\star \star \star}\end{array}$ & $\begin{array}{c}0.004 \\
(0.001)^{\star \star \star}\end{array}$ & $\begin{array}{c}0.005 \\
(0.002)^{\star *}\end{array}$ & $\begin{array}{c}0.004 \\
(0.000)^{\star \star \star}\end{array}$ & $\begin{array}{c}0.007 \\
(0.001)^{\star \star \star}\end{array}$ & $\begin{array}{c}0.003 \\
(0.001)^{\star \star \star}\end{array}$ & $\begin{array}{c}0.005 \\
(0.001)^{\star \star \star}\end{array}$ \\
\hline Exp. Res. ${ }^{\star}$ Experience Squared & $\begin{array}{c}0.000 \\
(0.000)\end{array}$ & $\begin{array}{c}0.000 \\
(0.005)\end{array}$ & $\begin{array}{c}0.000 \\
(0.000)\end{array}$ & $\begin{array}{c}0.000 \\
(0.000)\end{array}$ & $\begin{array}{c}0.000 \\
(0.000)^{\star *}\end{array}$ & $\begin{array}{c}0.000 \\
(0.000)^{\star *}\end{array}$ & $\begin{array}{l}0.000 \\
0.000\end{array}$ & $\begin{array}{l}0.000 \\
0.000\end{array}$ \\
\hline Exp. Res. ${ }^{*}$ Task Tenure & & $\begin{array}{l}(0.001)^{\star \star \star} \\
(0.001)^{\star \star \star}\end{array}$ & & $\begin{array}{c}-0.004 \\
(0.002)^{\star}\end{array}$ & & $\begin{array}{c}-0.004 \\
(0.001)^{\star \star \star}\end{array}$ & & $\begin{array}{c}-0.004 \\
(0.001)^{\star \star \star}\end{array}$ \\
\hline Exp. Res. ${ }^{\star}$ Occupation Tenure & $\begin{array}{l}-0.001 \\
(0.001)\end{array}$ & $\begin{array}{c}0.001 \\
(0.001)\end{array}$ & $\begin{array}{c}-0.001 \\
(0.001)\end{array}$ & $\begin{array}{c}0.002 \\
(0.002)\end{array}$ & $\begin{array}{c}-0.002 \\
(0.000)^{\star \star \star}\end{array}$ & $\begin{array}{c}0.000 \\
(0.000)\end{array}$ & $\begin{array}{c}-0.002 \\
(0.001)^{\star \star \star}\end{array}$ & $\begin{array}{r}0.000 \\
-0.001\end{array}$ \\
\hline Residual Occupation Tenure & $\begin{array}{c}0.066 \\
(0.003)^{\star \star \star}\end{array}$ & $\begin{array}{c}0.063 \\
(0.006)^{\star \star \star}\end{array}$ & $\begin{array}{c}0.039 \\
(0.005)^{\star \star \star}\end{array}$ & $\begin{array}{c}0.041 \\
(0.013)^{\star \star \star}\end{array}$ & $\begin{array}{c}0.039 \\
(0.001)^{\star \star \star}\end{array}$ & $\begin{array}{c}0.024 \\
(0.007)^{\star \star \star}\end{array}$ & $\begin{array}{c}0.032 \\
(0.003)^{\star \star \star}\end{array}$ & $\begin{array}{c}0.054 \\
(0.009)^{\star \star \star}\end{array}$ \\
\hline Occ. Res. ${ }^{*}$ Experience & $\begin{array}{c}-0.004 \\
(0.001)^{\star \star \star}\end{array}$ & $\begin{array}{c}-0.004 \\
(0.001)^{\star \star \star}\end{array}$ & $\begin{array}{c}-0.002 \\
(0.001)^{\star}\end{array}$ & $\begin{array}{l}-0.002 \\
(0.002)\end{array}$ & $\begin{array}{c}-0.002 \\
(0.000)^{\star \star \star}\end{array}$ & $\begin{array}{c}0.000 \\
(0.000)\end{array}$ & $\begin{array}{l}-0.001 \\
-0.001\end{array}$ & $\begin{array}{c}0.001 \\
(0.001)\end{array}$ \\
\hline Occ. Res. * Experience Squared & $\begin{array}{c}0.000 \\
(0.000)^{\star \star \star}\end{array}$ & $\begin{array}{c}0.000 \\
(0.000)^{\star \star \star}\end{array}$ & $\begin{array}{c}0.000 \\
(0.000)^{\star \star}\end{array}$ & $\begin{array}{c}0.000 \\
(0.000)\end{array}$ & $\begin{array}{c}0.000 \\
(0.000)^{\star \star \star}\end{array}$ & $\begin{array}{c}0.000 \\
(0.000)\end{array}$ & $\begin{array}{c}0.000 \\
(0.000)^{\star \star \star *}\end{array}$ & $\begin{array}{l}0.000 \\
0.000\end{array}$ \\
\hline Occ. Res.* Task Tenure & & $\begin{array}{c}0.005 \\
(0.001)^{\star \star \star}\end{array}$ & & $\begin{array}{c}0.004 \\
(0.002)^{\star \star}\end{array}$ & & $\begin{array}{c}0.002 \\
(0.000)^{\star \star \star}\end{array}$ & & $\begin{array}{c}0.001 \\
(0.001)\end{array}$ \\
\hline Occ. Res. ${ }^{\star}$ Occupation Tenure & $\begin{array}{c}-0.002 \\
(0.000)^{\star \star \star}\end{array}$ & $\begin{array}{c}-0.003 \\
(0.000)^{\star \star \star}\end{array}$ & $\begin{array}{c}-0.002 \\
(0.001)^{\star \star \star}\end{array}$ & $\begin{array}{c}-0.003 \\
(0.001)^{\star \star \star}\end{array}$ & $\begin{array}{c}-0.003 \\
(0.000)^{\star \star \star}\end{array}$ & $\begin{array}{c}-0.004 \\
(0.000)^{\star \star \star}\end{array}$ & $\begin{array}{c}-0.004 \\
(0.000)^{\star \star \star}\end{array}$ & $\begin{array}{c}-0.004 \\
(0.000)^{\star \star \star}\end{array}$ \\
\hline Residual Task Tenure & & $\begin{array}{c}0.018 \\
(0.006)^{\star \star \star}\end{array}$ & & $\begin{array}{c}0.000 \\
(0.035)\end{array}$ & & $\begin{array}{c}0.032 \\
(0.003)^{\star \star \star}\end{array}$ & & $\begin{array}{c}-0.05 \\
(0.020)^{\star \star}\end{array}$ \\
\hline Task Res. * Experience & & $\begin{array}{c}-0.003 \\
(0.001)^{\star \star}\end{array}$ & & $\begin{array}{c}0.001 \\
(0.002)\end{array}$ & & $\begin{array}{c}-0.003 \\
(0.001)^{\star \star \star}\end{array}$ & & $\begin{array}{c}0.001 \\
(0.001)\end{array}$ \\
\hline Task Res. * Experience Squared & & $\begin{array}{c}0.000 \\
(0.000)^{\star \star \star}\end{array}$ & & $\begin{array}{c}0.000 \\
(0.000)\end{array}$ & & $\begin{array}{c}0.0001 \\
(0.000)^{\star \star \star}\end{array}$ & & $\begin{array}{c}0.000 \\
(0.000)\end{array}$ \\
\hline Task Res.* Task Tenure & & $\begin{array}{c}0.001 \\
(0.001)^{\star}\end{array}$ & & $\begin{array}{l}-0.001 \\
(0.001)\end{array}$ & & $\begin{array}{c}0.000 \\
(0.001)\end{array}$ & & $\begin{array}{c}0.000 \\
(0.001)\end{array}$ \\
\hline Task Res. ${ }^{*}$ Occupation Tenure & & $\begin{array}{c}-0.004 \\
(0.001)^{\star \star \star}\end{array}$ & & $\begin{array}{c}-0.004 \\
(0.002)^{\star \star}\end{array}$ & & $\begin{array}{c}-0.003 \\
(0.000)^{\star \star \star}\end{array}$ & & $\begin{array}{c}-0.002 \\
(0.001)^{\star \star}\end{array}$ \\
\hline$P$ value for Joint Significance & $0 \%$ & $0 \%$ & $0 \%$ & $0 \%$ & $0 \%$ & $0 \%$ & $0 \%$ & $0 \%$ \\
\hline
\end{tabular}

Notes: The table reports the coefficients on the residuals and their interaction with the main regressors to control for selection in Table 9 . The column number in this table correspond to the column numbers (1) to (4) in Table 9. Standard errors are bootstrapped with 100 replications. The last column reports the p-value of the test for joint significance of the residuals and the interaction terms. See also notes to Table 9. 